\title{
Article \\ TNF $\alpha$ Mediates Inflammation-Induced Effects on PPARG Splicing in Adipose Tissue and Mesenchymal Precursor Cells
}

\author{
Simona Cataldi ${ }^{1}$ (D), Marianna Aprile ${ }^{1}$ (D), Daniela Melillo ${ }^{2}$, Inès Mucel ${ }^{3}$, Sophie Giorgetti-Peraldi ${ }^{3}$, \\ Mireille Cormont ${ }^{3}$, Paola Italiani ${ }^{2} \mathbb{D}$, Matthias Blüher ${ }^{4,5}{ }^{(D}$, Jean-François Tanti ${ }^{3} \mathbb{D}$, Alfredo Ciccodicola ${ }^{1,6, t}(\mathbb{D}$ \\ and Valerio Costa $1, *,+(\mathbb{D}$
}

1 Institute of Genetics and Biophysics "Adriano Buzzati-Traverso", CNR, Via P. Castellino 111, 80131 Naples, Italy; simona.cataldi@igb.cnr.it (S.C.); marianna.aprile@igb.cnr.it (M.A.); alfredo.ciccodicola@igb.cnr.it (A.C.)

2 Institute of Biochemistry and Cell Biology, CNR, Via P. Castellino 111, 80131 Naples, Italy; daniela.melillo@ibbc.cnr.it (D.M.); paola.italiani@ibbc.cnr.it (P.I.)

3 Université Côte d'Azur, Inserm UMR1065, C3M, Team Cellular and Molecular Pathophysiology of Obesity, 06204 Nice, France; ines.mucel@etu.univ-cotedazur.fr (I.M.); sophie.giorgetti-peraldi@inserm.fr (S.G.-P.); cormont@unice.fr (M.C.); tanti@unice.fr (J.-F.T.)

4 Medical Department III-Endocrinology, Nephrology and Rheumatology, University of Leipzig, 04103 Leipzig, Germany; matthias.blueher@medizin.uni-leipzig.de

5 Helmholtz Institute for Metabolic, Obesity and Vascular Research (HI-MAG) of the Helmholtz Zentrum München at the University of Leipzig and University Hospital Leipzig, Philipp-Rosenthal-Str. 27, 04103 Leipzig, Germany

6 Department of Science and Technology, University of Naples "Parthenope", 80143 Naples, Italy

* Correspondence: valerio.costa@igb.cnr.it; Tel.: +39-0816132617

+ These authors contributed equally to this work.

\section{check for}

Citation: Cataldi, S.; Aprile, M.;

Melillo, D.; Mucel, I.;

Giorgetti-Peraldi, S.; Cormont, M.; Italiani, P.; Blüher, M.; Tanti, J.-F.; Ciccodicola, A.; et al. TNF $\alpha$ Mediates Inflammation-Induced Effects on PPARG Splicing in Adipose Tissue and Mesenchymal Precursor Cells. Cells 2022, 11, 42. https://doi.org/ 10.3390/cells11010042

Academic Editor: Bruce A. Bunnell

Received: 10 August 2021

Accepted: 20 December 2021

Published: 24 December 2021

Publisher's Note: MDPI stays neutral with regard to jurisdictional claims in published maps and institutional affiliations.

Copyright: () 2021 by the authors Licensee MDPI, Basel, Switzerland. This article is an open access article distributed under the terms and conditions of the Creative Commons Attribution (CC BY) license (https:// creativecommons.org/licenses/by/ $4.0 /)$.

\begin{abstract}
Low-grade chronic inflammation and reduced differentiation capacity are hallmarks of hypertrophic adipose tissue (AT) and key contributors of insulin resistance. We identified PPARG $\triangle 5$ as a dominant-negative splicing isoform overexpressed in the AT of obese/diabetic patients able to impair adipocyte differentiation and PPAR $\gamma$ activity in hypertrophic adipocytes. Herein, we investigate the impact of macrophage-secreted pro-inflammatory factors on PPARG splicing, focusing on PPARG $\Delta 5$. We report that the epididymal AT of LPS-treated mice displays increased Pparg $\Delta 5 / \mathrm{cPparg}$ ratio and reduced expression of Pparg-regulated genes. Interestingly, pro-inflammatory factors secreted from murine and human pro-inflammatory macrophages enhance the PPARG $\Delta 5 / c P P A R G$ ratio in exposed adipogenic precursors. TNF $\alpha$ is identified herein as factor able to alter PPARG splicingincreasing PPARG 5 /cPPARG ratio-through PI3K/Akt signaling and SRp40 splicing factor. In line with in vitro data, TNFA expression is higher in the SAT of obese (vs. lean) patients and positively correlates with PPARG $\Delta 5$ levels. In conclusion, our results indicate that inflammatory factors secreted by metabolically-activated macrophages are potent stimuli that modulate the expression and splicing of PPARG. The resulting imbalance between canonical and dominant negative isoforms may crucially contribute to impair PPAR $\gamma$ activity in hypertrophic AT, exacerbating the defective adipogenic capacity of precursor cells.
\end{abstract}

Keywords: PPARG splicing; dominant negative isoform; inflammation; $\mathrm{TNF} \alpha$; adipocyte precursors; hypertrophic obesity

\section{Introduction}

Obesity is a chronic, relapsing progressive disease considered a driving force for insulin resistance and type-2 diabetes (T2D) [1,2]. Low-grade chronic inflammation in adipose tissue (AT) crucially contributes to obesity-related metabolic dysfunctions [3-5]. Indeed, the energy surplus can induce the enlargement of adipocyte size (hypertrophy), in turn leading to hypoxia, mechanical stress of the extracellular matrix, cell death and the secretion of pro-inflammatory cytokines [6-9]. These events trigger a chronic inflammatory 
response, stimulating the infiltration of macrophages $(M \Phi), T$ and dendritic cells $[3-5,9,10]$. In turn, the substantial accumulation and polarization of $M \Phi$ into pro-inflammatory and metabolically activated cells-associated with qualitative and quantitative genetic and epigenetic remodeling-increases local and systemic levels of cytokines and chemokines, correlated with insulin resistance and T2D (e.g., TNF $\alpha$, IL-6, IL1 $\beta$, CCL4) [11-15]. Indeed, $\mathrm{M} \Phi$-secreted factors impair the insulin-responsiveness of AT-residing adipocytes $[16,17]$ and the differentiation capacity of mesenchymal adipogenic precursors [12,18]. These molecules reduce the expression and activity of the peroxisome proliferator-activated receptor $\gamma(\operatorname{PPAR} \gamma)$ [19-22], the master regulator of adipogenesis and metabolic homeostasis [23-28]. However, the exact molecular mechanisms determining the functional impairment of PPAR $\gamma$ in insulin-resistant AT have not been fully elucidated. Our recent identification and characterization of $\operatorname{PPAR} \gamma \Delta 5$, a naturally occurring dominant negative isoform of PPAR $\gamma$ generated by exon 5 skipping, revealed a new layer in the regulation of PPARG [29]. Indeed, increased levels of PPAR $\gamma \Delta 5$-measured in the subcutaneous AT (SAT) of patients with overweight and obesity-impairs the in vitro differentiation ability of adipocyte precursor cells [29]. Increased PPARG $\Delta 5 /$ CPPARG ratio was also measured in our recently generated in vitro model of human hypertrophic-like adipocytes [30]. Moreover, the PPARG $\triangle 5 /$ PPARG relative amount in the SAT of overweight and obese patients correlated positively with BMI [29] and negatively with SLC2A4 (i.e., GLUT4) mRNA levels [30], suggesting a contribution of $\operatorname{PPAR} \gamma \Delta 5$ in hypertrophic obesity.

Hence, in this work, we investigated whether the balance between canonical and dominant negative PPAR $\gamma$ isoforms is affected by pro-inflammatory factors and if such alteration contributes to the impaired neo-adipogenesis and insulin-resistance in hypertrophic AT. Herein, we demonstrate that $M \Phi$-secreted pro-inflammatory factors affect PPARG splicing, increasing the PPARG $\Delta 5 /$ CPPARG ratio. Notably, we report that TNF $\alpha$ induces the activation of the serine/arginine-rich protein 40 (SRp40) and PI3K/Akt signaling, representing the most powerful inflammatory stimulus able to modulate PPARG expression and splicing. Moreover, TNFA and PPARG 5 mRNA levels show a positive correlation in the SAT of obese patients, further supporting PPARG splicing alteration as a feature of inflamed AT. Our work reveals a previously unrecognized role of macrophage-secreted factors on PPARG regulation, indicating the inflammation-mediated alteration of PPARG splicing in adipogenic precursors as a new potential contributor to the defective neo-adipogenesis of hypertrophic adipose tissue.

\section{Materials and Methods}

\subsection{Human Samples}

Adipose tissue samples were obtained from donors to the Leipzig Obesity Bio Bank $\left(\mathrm{n}=55\right.$; mean age $=57.6 \pm 16.7$ years; mean $\left.\mathrm{BMI}=32.3 \pm 9.9 \mathrm{~kg} / \mathrm{m}^{2}\right)$ undergoing bariatric surgery [31,32] and available through previously reported collaborations $[29,30]$. The study has been reviewed and approved by the ethics committee of Leipzig University, Germany (approval numbers: 159-12-21052012 and 017-12-23012012), and carried out in accordance with the Declaration of Helsinki, the Bioethics Convention (Oviedo) and the EU Directive on Clinical Trials (Directive 2001/20/EC). Patients were randomly selected from the human tissue biopsy bank held by Prof. Bluher, with more than 3700 subjects having a wide range of overweight and obesity (BMI range: $13-129 \mathrm{~kg} / \mathrm{m}^{2}$ ), body fat distribution, insulin sensitivity and glucose tolerance. The random selection of samples, as well as the exclusion criteria of individuals were applied as described in Aprile et al. (2018). Briefly, individuals with the following criteria were excluded: age $<18$ years, obesity secondary to endocrine diseases, gastrointestinal inflammatory diseases, risk of upper gastrointestinal bleeding, mental disorders, previous or current malignancies, habitual consumption of alcohol or drugs. Patients were categorized according to their BMI into three subgroups: lean $\left(\mathrm{BMI} \leq 25 \mathrm{~kg} / \mathrm{m}^{2} ; \mathrm{n}=14\right)$, overweight $\left(25<\mathrm{BMI}<30 \mathrm{~kg} / \mathrm{m}^{2} ; \mathrm{n}=17\right)$ and obesity (BMI $\left.\geq 30 \mathrm{~kg} / \mathrm{m}^{2} ; \mathrm{n}=24\right)$. 


\subsection{Animals}

Epididymal AT samples were isolated from C57BL/6J mice ip-injected with LPS $(2 \mu \mathrm{g} / \mathrm{g}$ of body weight, InvivoGen, San Diego, USA) or with vehicle (NaCL $0.9 \%)$ for $5 \mathrm{~h}$. Mice and adipose tissue samples were already described in a previous publication [33]. The study was conducted according to the Principles of Laboratory Animal Care (NIH publication no. 85-23, revised 1985) and the European Union guidelines on animal laboratory care. All procedures were approved by Animal Care Committee of the Faculty of Medicine of Nice-Sophia Antipolis University, Nice, France, and the French ministry of national education (\#05116.02 and \#201505\&9143792_v2).

\subsection{Cell Cultures}

Human in vitro monocytes, i.e., THP-1 (Cat\#TIB-202), hTERT immortalized adiposederived mesenchymal stem cells (hMSCs; Cat\# SCRC4000)were purchased from the American Type Culture Collection (ATCC). HMSCs were cultured in DMEM-F12 (1:1) supplemented with $10 \%$ American fetal bovine serum (FBS), $2 \mathrm{mM}$ glutamine, 30 units $/ \mathrm{mL}$ penicillin and $30 \mu \mathrm{g} / \mathrm{mL}$ streptomycin. THP-1 cells were grown in suspension with RPMI supplemented with 10\% American fetal bovine serum (FBS), $2 \mathrm{mmol} / \mathrm{L}$ glutamine, 100 units $/ \mathrm{mL}$ penicillin and 100 units $/ \mathrm{mL}$ streptomycin.

Human monocytes were isolated from the fresh buffy coats of healthy donors recruited at the Transfusional Center of the Hospital Policlinico at "Federico II" University of Naples (Italy) after informed consent according to the Declaration of Helsinki. PBMCs were obtained by density centrifugation over Ficoll-Paque plus (GE Healthcare, Bio-sciences AB, Uppsala, Sweden), and, subsequently, CD14+ monocytes were isolated from PBMCs using anti-CD14 antibody-bearing magnetic microbeads (Miltenyi Biotec, Bergisch-Gladbach, Germany), according to the manufacturer's instructions. Primary monocytes were resuspended in RPMI-1640 medium (GIBCO, Life Technologies, Carlsband, CA, USA) containing 5\% heat-inactivated human AB serum (Lonza, Pearland, TX, USA) and $50 \mathrm{mg} / \mathrm{mL}$ gentamicin (Sigma-Aldrich Inc., St. Louis, MO, USA) and cultured at a density of $0.5 \times 10^{6}$ cells $/ \mathrm{mL} /$ well in 24-well culture plates (Costar, Corning, NY, USA). The purity of isolated cells was determined microscopically after cytocentrifugation and differential staining with a modified Wright-Giemsa dye (Diff Quik, Medion Diagnostics AG, Düdingen, Switzerland), while viability was determined by trypan blue dye exclusion. Only preparations with $>98 \%$ purity was used.

The J774A.1 mouse macrophage cell line (Cat\#85011428) was obtained from the European Collection of Authenticated Cell Culture and 3T3-L1 mouse fibroblasts (Cat\#CL-173 ${ }^{\mathrm{TM}}$ ) from ATCC. J774A.1 cells were cultured in DMEM supplemented with 5\% American fetal bovine serum (FBS), $2 \mathrm{mmol} / \mathrm{L}$ glutamine, 100 units $/ \mathrm{mL}$ penicillin and 100 units $/ \mathrm{mL}$ streptomycin. 3T3-L1 fibroblasts were cultured in DMEM supplemented with $10 \%$ of newborn calf serum, $2 \mathrm{mmol} / \mathrm{L}$ glutamine, 100 units $/ \mathrm{mL}$ penicillin and 100 units $/ \mathrm{mL}$ streptomycin.

All above-mentioned cell cultures, except for 3T3-L1 cells, were maintained in a humidified atmosphere of $95 \%$ air and $5 \% \mathrm{CO}_{2}$ at $37^{\circ} \mathrm{C}$. 3T3-L1 cells were maintained in a humidified atmosphere of $95 \%$ air and $7 \% \mathrm{CO}_{2}$ at $37^{\circ} \mathrm{C}$.

All media, sera and antibiotics were purchased from Thermo Fisher Scientific (Waltham, MA, USA).

\subsection{Human Adipocyte Differentiation}

HMSCs were differentiated in mature adipocytes as previously described $[29,30]$. Briefly, cells were plated at 3 to $4 \times 10^{3} / \mathrm{cm}^{2}$ density and grown to maximum confluence (i.e., timepoint, $\mathrm{T}=0 \mathrm{~h}$ ). Adipocyte differentiation was induced by alternatively using two different mixes: an adipocyte differentiation induction mix and a maintaining mix (AIM and AMM, respectively). AIM contains insulin $850 \mathrm{nM}$ (Humulin R, Lilly, Indianapolis, IN, USA, Cat\#AIC025707011/M), dexamethasone $10 \mu \mathrm{M}$ (Sigma-Aldrich Inc., St. Louis, MO, USA, Cat\#D4902), 3-isobutyl-1-methylXanthine $0.5 \mu \mathrm{M}$ (Sigma-Aldrich Inc., St. Louis, MO, USA, Cat\#I7018), biotin 33 M (Sigma-Aldrich Inc., St. Louis, MO, USA, Cat\#B4639), 
pantothenate $17 \mu \mathrm{M}$ (Sigma-Aldrich Inc., St. Louis, MO, USA, Cat\#P5155) and rosiglitazone $1 \mu \mathrm{M}$ (Sigma-Aldrich Inc., St. Louis, MO, USA, Cat\#R2408). AMM consists of $850 \mathrm{nM}$ insulin and $1 \mu \mathrm{M}$ rosiglitazone. Cells reached complete adipocyte differentiation within 19-21 days after the first induction $(\mathrm{T}=21 \mathrm{~d})$.

\subsection{Differentiation of Primary and InVitro Human Macrophages}

THP-1 human monocytes were seeded in a complete culture medium supplemented with 50ng/mL of Phorbol 12-Myristate 13-Acetate (PMA, Sigma-Aldrich Inc, St. Louis, MO, USA, Cat\#P8139) at $10 \times 10^{6} / 10 \mathrm{~mL}$ density in a $10 \mathrm{~cm}$ plate. The medium, containing $50 \mathrm{ng} / \mathrm{mL}$ of PMA, was replaced every two days until a complete macrophage differentiation was reached (i.e., 6 days after induction).

In order to generate in vitro monocyte-derived macrophages, fresh primary monocytes - isolated as described above-were cultured for 7 days in complete medium supplemented with $50 \mathrm{ng} / \mathrm{mL}$ M-CSF (R\&D Systems, Minneapolis, MN) and replaced at day 3. Terminally differentiated macrophages (i.e., 8 days after differentiation induction) were incubated for $24 \mathrm{~h}$ in fresh complete medium (i.e., control cells) or supplemented with LPS (10 ng/mL) of Escherichia coli O55:B5 (Sigma-Aldrich Inc., St. Louis, MO, USA) and IFN $\gamma 20 \mathrm{ng} / \mathrm{mL}$ (R\&D Systems, Minneapolis, MN, USA) for cell activation in pro-inflammatory macrophages or supplemented with IL-10 (20 ng/mL; R\&D Systems, Minneapolis, MN, USA) to obtain anti-inflammatory macrophages.

\subsection{Conditioned Medium Preparation}

The conditioned medium of human macrophages differentiated from THP-1 was obtained stimulating — or not— the cells with LPS (20 ng/mL; Sigma-Aldrich Inc, St. Louis, MO, USA, Cat\# L2630) in RPMI supplemented with $0.5 \%$ bovine serum albumin. After $24 \mathrm{~h}$, the medium was collected and centrifuged at $1000 \times \mathrm{g}$ rpm for $10 \mathrm{~min}$, and cell-free supernatant was used for treating hMSCs, as described below. Similarly, the conditioned media of primary macrophages-both pro-inflammatory (i.e., LPS/IFN $\gamma$-induced macrophages) and anti-inflammatory (IL10-induced macrophages) - were obtained by collecting supernatants after $24 \mathrm{~h}$ of stimulation (as described above) and centrifugation at $1000 \times g \mathrm{rpm}$ for $10 \mathrm{~min}$ at $4{ }^{\circ} \mathrm{C}$. Finally, J774A.1 mouse macrophages were stimulated or not with $0.5 \mathrm{ng} / \mathrm{mL}$ of LPS in DMEM supplemented with 5\% FBS for $24 \mathrm{~h}$, and the medium was collected and centrifuged at $1300 \times g \mathrm{rpm}$ for $5 \mathrm{~min}$.

\subsection{Murine Adipocyte Differentiation}

3T3-L1 mouse fibroblasts were cultured at confluence and induced to differentiate in mature adipocytes by two differentiation mixes. Thus, control (i.e., DMEM-5\% FBS or DMEM-5\% FBS plus LPS $0.5 \mathrm{ng} / \mathrm{mL}$ ) or conditioned media (collected from LPS stimulating and not J774A.1 macrophages) were supplemented by isobutyl methylxanthine $0.5 \mu \mathrm{M}$ (Sigma-Aldrich Inc., St. Louis, MO, USA, Cat\# I5879), dexamethasone $0.25 \mu \mathrm{M}$ (Sigma-Aldrich Inc., St. Louis, MO, USA, Cat\# D1756), rosiglitazone $10 \mu \mathrm{M}$ (Enzo Life Science, Farmingdale, NY, USA, Cat\# ALX-350-125) and insulin $5 \mu \mathrm{g} / \mathrm{mL}$ (Humulin, Lilly, Indianapolis, IN, USA, Cat\# HI0290). After two days, the cells were treated with insulin $(5 \mu \mathrm{g} / \mathrm{mL})$ and rosiglitazone $(10 \mu \mathrm{M})$ for an additional two days. Then, fresh medium-i.e., without the adipogenic cocktail —was added until the adipocyte phenotype appeared in more than $90 \%$ of the cells (i.e., 8 days after induction) by microscopic visualization.

\subsection{Oil Red O Staining}

Lipid accumulation was measured by Oil red O staining, as previously described [20,29]. In detail, murine adipocytes (i.e., 8 days after adipogenesis induction) were fixed with $4 \%$ paraformaldehyde for $20 \mathrm{~min}$, washed three times with PBS and then stained with Oil red O (Sigma-Aldrich Inc., St. Louis, MO, USA, Cat\# O0625) for $15 \mathrm{~min}$. Cells were washed, and Oil red $\mathrm{O}$ was eluted by isopropanol $100 \%$. The quantification of accumulated lipids was performed by optical density measurement at $510 \mathrm{~nm}$ using the spectrophotometer. 
The background signal was estimated in undifferentiated cells and subtracted from optical density values. The significance of the differences between the samples was calculated by a two-tailed one sample Student's $t$ test.

\subsection{Cell Treatments}

HMSCs (i.e., $\mathrm{T}=0 \mathrm{~h}$ ) or hMSCs-derived mature adipocytes (i.e., $\mathrm{T}=21 \mathrm{~d}$ after adipocyte-differentiation induction) were treated for $24 \mathrm{~h}$ with conditioned medium collected by human macrophages (differentiated from THP-1 as above described) or with RPMI 0.5\% BSA supplemented or not with $20 \mathrm{ng} / \mathrm{mL}$ LPS, used as control. Moreover, hMSCs (i.e., $\mathrm{T}=0 \mathrm{~h}$ ) were treated for $24 \mathrm{~h}$ with culture supernatants of primary not-polarized macrophages or were activated by LPS/IFN $\gamma$ or IL-10.

To investigate PPARG mRNA half-life, hMSCs were treated for $3 \mathrm{~h}$ with 2 or $5 \mathrm{mg} / \mathrm{mL}$ of actinomycin D (Sigma-Aldrich Inc., St. Louis, MO, USA, Cat\# A1410) in complete culture medium. Cells treated with the vehicle (i.e., dimethyl sulfoxide, DMSO) were used as control.

HMSCs were treated with human recombinant cytokines or with the vehicle (i.e., PBS) in DMEM-F12 supplemented with 1\% FBS. Specifically, cells were treated for $24 \mathrm{~h}$ (for gene expression analysis) or for $30 \mathrm{~min}$ (for protein assays) with $10 \mathrm{ng} / \mathrm{mL}$ of IL-6 (Thermo Fisher Scientific, Waltham, MA, USA, Cat\# PHC0066), IL-8 (Preprotech, Rocky Hill, NJ, USA, Cat\#200-08), IL-1ß (Preprotech, Rocky Hill, NJ, USA, Cat\# 200-01B) cytokines or increasing doses of TNF $\alpha$ protein (i.e., 5, 10 or $20 \mathrm{ng} / \mathrm{mL}$; SinoBiological, Beijing, China, Cat\# 10602-HNAE-50).

Conditioned medium collected by THP-1-derived macrophages was incubated with $0.5 \mathrm{mg} / \mathrm{mL}$ of human neutralizing antibody against TNF $\alpha$ (R\&D system, Minneapolis, USA, Cat\# MAB610-SP) or anti-IgG1 Isotype (R\&D system, Minneapolis, MN, USA, Cat\# MAB002) for $2 \mathrm{~h}$ at $4{ }^{\circ} \mathrm{C}$. Then, the medium supplemented with antibodies was added to hMSCs for $24 \mathrm{~h}$ for mRNA expression analysis and $30 \mathrm{~min}$ for protein assays. Cells treated with RPMI 0.5\% BSA plus anti-IgG1 Isotype were used as control.

Moreover, hMSCs were treated for $2 \mathrm{~h}$ with DMEM 1\% FBS supplemented with 300nM of Wortmannin (Thermo Fisher Scientific, Waltham, Massachusetts, USA, Cat\# PHZ1301), KHCB19 (Santa Cruz Biotechnology, Dallas, TX, USA, Cat\# 1354037-26-5) or the vehicle (i.e., DMSO). Then, cells were exposed to fresh medium supplemented with $10 \mathrm{nM}$ of Wortmannin/KHCB19/vehicle and human recombinant TNF $\alpha$ protein (10 or $20 \mathrm{ng} / \mathrm{mL}$ ) for an additional $30 \mathrm{~min}$ to analyze protein phosphorylation or $24 \mathrm{~h}$ for mRNA expression analysis.

In addition, hMSCs were treated for $24 \mathrm{~h}$ with conditioned medium collected from THP-1-derived macrophages plus SRPIN340 $10 \mu \mathrm{M}$ (StressMarq Biosciences Inc., Victoria, Canada, SIH-514, Cat\# 218156-96-8) or with the vehicle (i.e., DMSO).

3T3-L1 mouse fibroblasts (i.e., $\mathrm{T}=0 \mathrm{~h}$ ) were exposed for $24 \mathrm{~h}$ to DMEM-1\% FBS supplemented with $10 \mu \mathrm{g} / \mathrm{mL}$ of mouse recombinant TNF $\alpha$ (Preprotech, Rocky Hill, NJ, USA, Cat\# 315-01A), IL-1ß (Preprotech, Rocky Hill, NJ, USA, Cat\# 211-11B) cytokines or with the vehicle (i.e., PBS).

For all treatments, cells were starved for $18 \mathrm{~h}$ with culture medium without serum.

\subsection{Cell Transfection}

HMSCs were transfected with two different siRNAs designed against SRSF5 (IDT, Coralville, Johnson County, IA, USA, hs.Ri.SRSF5.13.1) or with scrambled siRNAs, by using Lipofectamine 3000 (Thermo Fisher Scientific, Waltham, Massachusetts, MN, USA, Cat\# L3000001), according to the manufacturer's instructions. Cell transfection was carried out in culture medium without antibiotics and serum. After $6 \mathrm{~h}$, transfected cells were fed with medium supplemented with $10 \%$ FBS. The efficiency of silencing was calculated by quantitative PCR assays (qPCR) after 24 and $48 \mathrm{~h}$ of cell transfection, using different siRNAs in single or in combination. The siRNA hs.Ri.SRSF5.13.1 (40 nM) induced the silencing of SRSF5 with estimated efficiency of about $75 \%$ and was selected for further 
analysis. After $18 \mathrm{~h}$ of transfection, SRSF5-knockdown cells were treated for $24 \mathrm{~h}$ with human recombinant TNF $\alpha$ cytokine $(10$ or $20 \mathrm{ng} / \mathrm{mL})$ or with the conditioned medium of THP-1-derived macrophages.

\subsection{RNA Isolation, RT-PCR and Quantitative PCR}

Epididymal adipose tissue from C57BL/6J mice was homogenized by using Precellys tissue homogenizer. Total RNA was isolated from homogenized tissues and cell lines byTRIzol Reagent (Thermo Fisher Scientific, Waltham, Massachusetts, MN, USA, Cat\# 15596026), according to the manufacturer's instructions. Isolated RNA was quantified with NanoDrop spectrophotometer and was reverse transcribed using "High-Capacity cDNA Reverse Transcription kit" (Thermo Fisher Scientific, Waltham, Massachusetts, MN, USA, Cat\# 4368813). Gene expression analysis was performed by quantitative PCR assays using iTaq Universal Sybr Green Supermix (Bio-Rad, Hercules, CA, USA, Cat\# 1725125), according to the manufacturer's instructions, on a CFX Connect Detection System (Bio-Rad, Hercules, CA, USA). The specific primer pairs were designed using the Oligo 4.0 program and are listed in Table $\mathrm{S} 1$. The specificity of the amplification reaction was confirmed by melt curve analysis. PPIA, RPS23 and 3664 were selected as reference genes for analyzing human and mouse samples, respectively. Relative expression analysis was performed using the $2^{-\Delta \Delta C t}$ method, except for the analysis of TNFA expression levels assessedin the Leipzig cohort by the $\Delta \mathrm{Ct}$ method. All reactions were performed in duplicate in at least three independent experiments.

\subsection{Western Blot}

Lysates were harvested from hMSCs by a RIPA lysis buffer containing Halt Protease and Phosphatase Inhibitor Cocktail (Thermo Fisher Scientific, Waltham, Massachusetts, USA). Protein content was determined using the Bradford protein assay (BioRad, Hercules, CA, USA, Cat\# 5000205), and $60 \mu \mathrm{g}$ of lysates were separated on 12\% SDS-PAGE and transferred to PDVF membranes. Membranes were blocked with Tris-buffered saline-Tween (TBST) containing 4\% non-fat dried milk and incubated overnight with primary antibodies against the phospho-epitope of SR proteins (1:500, Merck Millipore, Darmstadt, Germany, clone 1H4, Cat\# MABE50), the phospho-Akt at Ser473 residue (1:800; Biolegend, San Diego, CA, USA, Cat\# 649001) or total Akt1 (1:1000; Biolegend, San Diego, CA, USA, Cat\# 680302). After incubation for $1.5 \mathrm{~h}$ at room temperature with anti-IgG (HRP)-conjugated secondary antibody (1:4000, Bio-Rad, Hercules, CA, USA, Cat\# 170-6515/A28175), signal detection was performed by Pierce ECL Western Blotting Substrate (Thermo Fisher Scientific, Waltham, MA, USA). The shown autoradiographs are representative of at least three independent experiments. Densitometric data analysis was performed on pixel density by GelQuant.NET software (www.biochemlabsolutions.com (accessed on 31 January 2021)). Intensity values were normalized using Hsp90 as the housekeeping gene and compared to signals detected in reference samples.

\subsection{ELISA}

Levels of the inflammatory cytokines were determined by ELISA (R\&D Systems, MN, USA) in cell-free supernatants according to the manufacturer's instructions. The absorbance of assay wavelength was measured at $450 \mathrm{~nm}$ using a Cytation 3 imaging reader (BioTek, Winooski, VT, USA).

\subsection{Statistics}

All data are expressed as means \pm SEM, except for expression data in human biopsies that are expressed as median \pm DEVST. All assays were performed at least in triplicate. A Shapiro-Wilk test ("shapiro.test function") implemented in R language was used for assessing the normal distribution of data. Statistical significance of differences between testing and control samples was evaluated by a two-tailed (one or two sample) Student's $t$ test (GraphPad Software Inc., La Jolla, CA, USA). Gene expression differences in the German cohort were analyzed by a Mann-Whitney $U$ test. A linear model implemented in 
R language (lmp function) was used for correlation analysis, as described elsewhere [29]. Boxplots showing TNFA mRNA expression analysis were generated in $\mathrm{R}$ using the ggplot2 library and custom scripts. Differences between testing and control samples were defined as significant as $p$ value $\leq 0.05$.

\section{Results}

\subsection{The Inflammatory Milieu Affects Pparg Expression and Splicing In Vitro and In Vivo}

Pro-inflammatory stimuli suppress PPAR $\gamma$ transcriptional activity in murine primary adipocytes and pre-adipocyte cell lines linking the inflammation of AT to insulin resistance in obese patients [19]. We recently reported the increase of PPARG $\Delta 5$ and of the PPARG 5 /cPPARG ratio in the SAT of obese patients [29], and a tight association with hypertrophic - rather than "metabolically-healthy" hyperplastic-obesity and its related metabolic alterations [30].

To assess in vivo whether inflammation-hallmark of hypertrophic obesity-affects PPARG splicing, we measured the relative abundance of canonical (cPparg) and dominant negative (Pparg $\Delta 5)$ Pparg transcripts in the epididymal AT of a well-established mouse model of systemic inflammation (previously described in Pastor et al., 2017) [33]. As expected, Pparg transcription is markedly repressed (about $70 \% ; p=0.0027$ ) in the epididymal fat of LPS-injected lean mice (Figure 1A, left panel) in line with previous findings [19]. Conversely, Pparg $\Delta 5 \mathrm{mRNA}$ levels are not affected (Figure 1A, left panel), determining in turn a 3.5-fold increase $(p=0.024)$ of Pparg $\Delta 5 / c P$ parg ratio (Figure $1 \mathrm{~A}$, right panel). This finding points out a previously unrecognized effect of inflammation on Pparg splicing in the AT. Accordingly, in line with the downregulation of cPparg levels and increased Pparg $\Delta 5 / c P$ parg ratio, the expression of Adipoq, Slc2a4 and Cd36-validated Ppar $\gamma$ target genes-is significantly reduced (Figure 1B), as we similarly observed in human lipid-engulfed hypertrophic adipocytes [30].

Moreover, our previous findings indicate that high PPAR $\gamma \Delta 5$ levels are associated with impaired adipogenic capacity of precursor cells [29], which represents a hallmark of hypertrophic obesity. Therefore, we explored Pparg splicing in murine precursor cells differentiating toward mature adipocytes in presence of a pro-inflammatory microenvironment. Hence, 3T3-L1 cells were induced to differentiate in the presence of conditioned media (CM) collected from murine J774.A1 (macrophage-like, M $\Phi$ cell line) activated and not with LPS. Interestingly, the analysis of the relative variation of all Pparg transcripts along the adipogenic process reveals that only the secretome of LPS-activated M $\Phi$ markedly affects Pparg splicing, inducing an increase of Pparg $\Delta 5 / c$ Pparg ratio in terminally differentiated adipocytes (1.5-fold, $p=0.03$; Figure $1 \mathrm{C}$ and Figure S1A,B). As a consequence, pro-inflammatory microenvironment induces an impairment of the adipogenic differentiation (Figure 1D) paralleled by the downregulation of Ppar $\gamma$ target genes (Figure 1E), according to in vivo data (Figure 1B).

These results indicate that the inflammatory microenvironment of the AT affects Pparg splicing, altering the relative amount between canonical and dominant negative isoforms. 


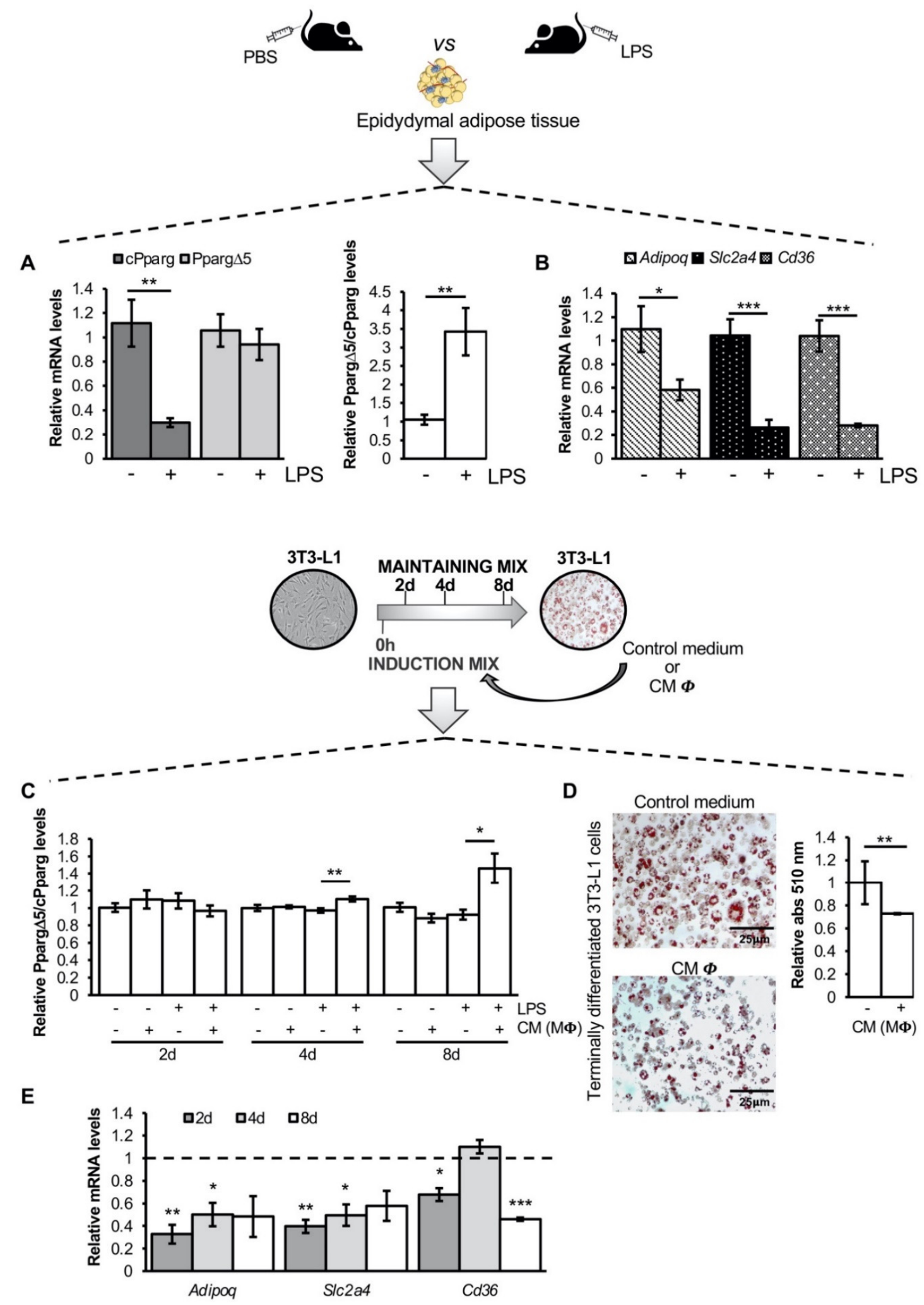

Figure 1. Inflammation affects Pparg expression and splicing in vitro and in vivo: (A) Relative mRNA quantification (qPCR) of canonical Pparg transcripts (cPparg), Pparg $\Delta 5$ (left panel), Pparg $\Delta 5 / c P$ parg ratio (right panel) and Ppar $\gamma$ target genes (i.e., Adipoq, Slc2a4 and $C d 36,(\mathbf{B})$ ) in epididymal adipose 
tissue of C57BL/6JB-LPS injected mice $(n=6)$. Epididymal adipose tissue from control mice $(n=7)$ was used as reference samples and $36 b 4$ as reference gene. Data are reported as mean \pm SEM of independent experiments. ${ }^{*} p \leq 0.05,{ }^{* *} p \leq 0.01$ and ${ }^{* * *} p \leq 0.001$. (C) Relative mRNA quantification (qPCR) of the Pparg $\Delta 5 /$ cPparg ratio at different time points of 3T3-L1 adipocyte differentiation (i.e., 2, 4 and 8 days upon differentiation induction) carried out in presence of conditioned medium $(\mathrm{CM})$ of J774.A1 macrophages (MФ) activated and not with LPS. 3T3-L1 differentiated in mature adipocytes with control medium with or without LPS were used as reference samples. 3664 was used as reference gene. Data are reported as mean \pm SEM of at least six independent experiments. ${ }^{*} p \leq 0.05,{ }^{* *} p \leq 0.01$. (D) Representative images of 3T3-L1 differentiated in mature adipocytes (i.e., 8 days upon differentiation induction) in presence and not of CM collected from LPS activated J774.A1 MФ (scale bar $25 \mu \mathrm{m}$ ). Lipid accumulation was measured by optical determination of Oil red $\mathrm{O}$ staining and reported in the bar graph. 3T3-L1 terminally differentiated in mature adipocytes with control medium plus LPS were used as reference samples. Data are reported as mean \pm SEM of three independent experiments. ${ }^{* *} p \leq 0.01$. (E) Relative mRNA quantification (qPCR) of Ppar $\gamma$ target genes (i.e., Adipoq, Slc2a4 and Cd36) at different time points of 3T3-L1 adipocyte differentiation (i.e., 2, 4 and 8 days upon differentiation induction) carried out in presence of CM of LPS activated J774.A1 cells. 3T3-L1 differentiated in mature adipocytes with control medium plus LPS were used as reference samples (dotted line) and 3664 as reference gene. Data are reported as mean $\pm \mathrm{SEM}$ of at least three independent experiments. ${ }^{*} p \leq 0.05,{ }^{* *} p \leq 0.01$ and ${ }^{* *} p \leq 0.001$.

\subsection{Pro-Inflammatory Macrophage Secretome Perturbs PPARG Splicing in Human Mesenchymal} Stem Cells

To determine whether inflammation also affects the PPARG splicing pattern in humans - similarly to that observed in mouse models-the relative abundance of canonical and dominant negative PPARG transcripts was measured in hMSCs and in vitrodifferentiated adipocytes exposed to the conditioned media of human $M \Phi$ differentiated from THP-1 monocytes activated and not with LPS (Figure 2A, upper panel). As shown in Figure 2A (lower left panel), the exposure of undifferentiated hMSCs to conditioned media of LPS-activated MФ (THP-1) causes a drop in the expression of all PPARG mRNAs, but with a more pronounced downregulation (about $80 \%$ reduction) of canonical transcripts $(p=0.0001)$. Accordingly, PPARG $\Delta 5 / c P P A R G$ ratio shows a 2.6-fold increase in exposed cells (Figure 2A, $p=0.0214$; lower left panel). In mature adipocytes-differentiated in vitro from hMSCs $(\mathrm{T}=21 \mathrm{~d}$ )-exposed to LPS-activated M $\Phi$ (THP-1)-conditioned media, a significant drop in the levels of cPPARG (about 95\% reduction; $p=0.0038$ ) and PPARG $\Delta 5$ (about 91\% reduction; $p=0.0004$ ) transcripts is observed (Figure 2A, lower right panel). However, likewise mature murine adipose cells (Figure 1C), PPARG 5 /cPPARG ratio markedly increases (about 2-fold; $p=0.0115$; Figure 2A, lower right panel).

Considering that PPARG 55 inversely correlates with the adipogenic capacity of hMSCs [29] and that inflammation perturbs PPARG splicing in these cells (Figure 2A), we investigated which inflammatory stimuli may account for the unbalanced PPARG 5 /cPPARG ratio. Hypertrophic AT is characterized by reduced adipogenesis and massive increase of pro-inflammatory macrophages by both infiltration and local proliferation [34]. Thus, we exposed hMSCs to the conditioned media of ex vivo-isolated human primary monocytes polarized toward two opposite distinct fates: pro-inflammatory (i.e., LPS/IFN $\gamma$-induced M $\Phi$ ) or anti-inflammatory (IL10-induced M $\Phi$ ) macrophages. As expected by our previous observation (Figure 2A), hMSCs exposed to the secretome of human primary pro-inflammatory MФ display a strong transcriptional repression of the entire PPARG locus (Figure 2B). Strikingly, a more pronounced reduction is observed for canonical PPARG transcripts (about $60 \%$ reduction; $p=0.0001$; Figure 2B, left panel), resulting in a 1.5-fold increase of PPARG 5 /cPPARG ratio ( $p=0.0208$; Figure $2 \mathrm{~B}$, right panel). On the other hand, the secretome of primary anti-inflammatory $M \Phi-$ known to promote adipocyte differentiation [35] -induces a 2-fold increase of both canonical and dominant negative PPARG transcripts ( $p=0.0061$ and $p=0.076$ respectively; Figure $2 \mathrm{~B}$, left panel), with no effects on their relative ratio ( $p=0.9228$; Figure $2 \mathrm{~B}$, right panel). 
A
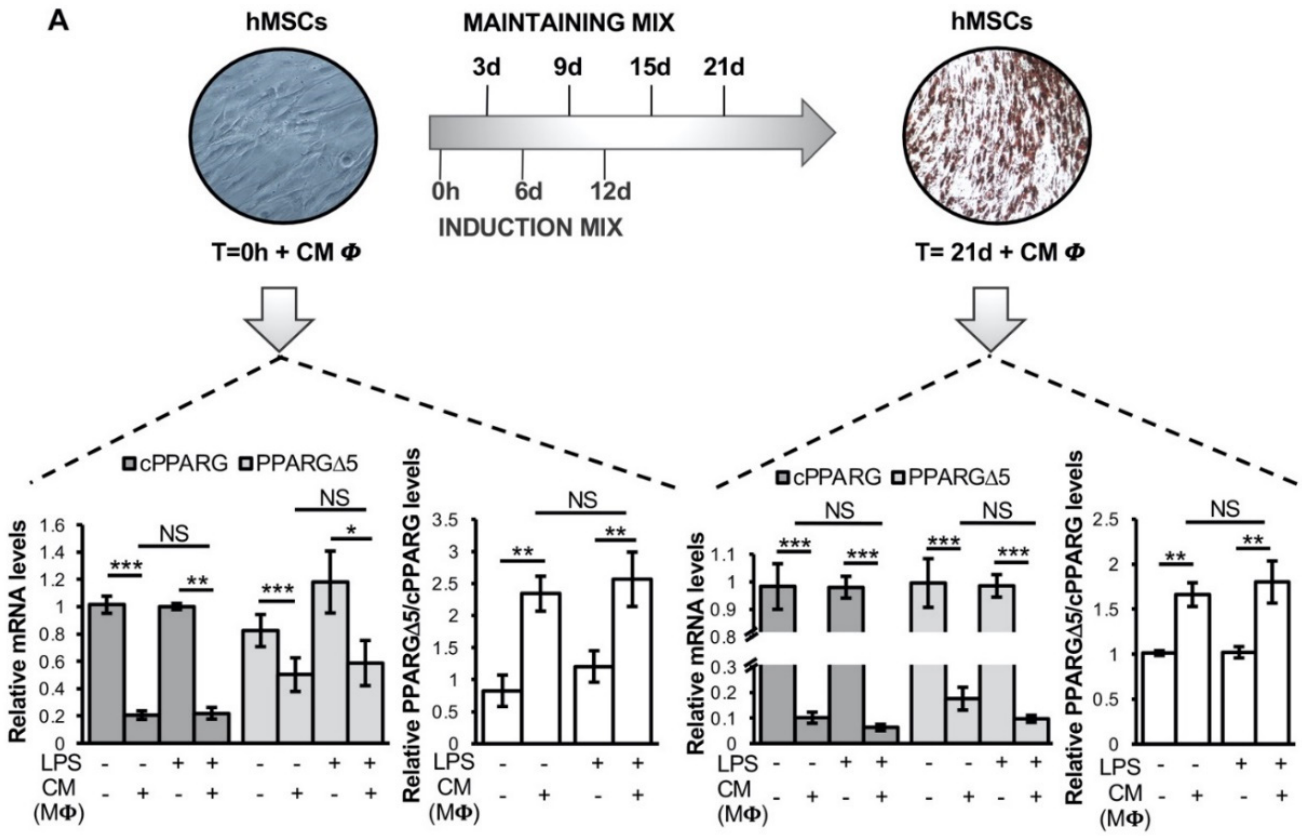

B

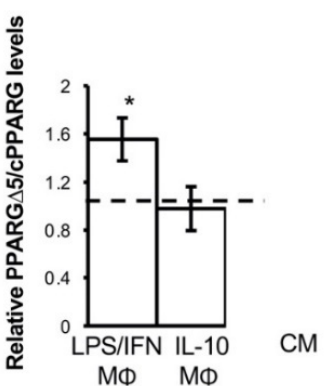

C
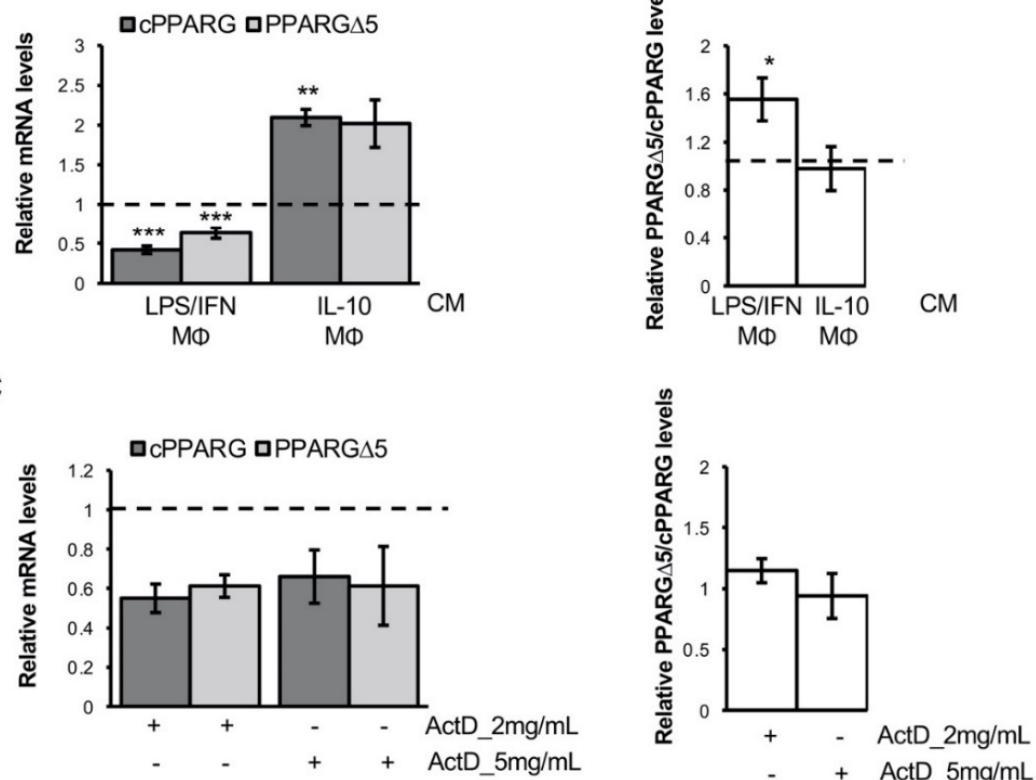

Figure 2. Human pro-inflammatory macrophages secretome perturbs PPARG splicing in human mesenchymal stem cells: (A) Representative images (upper panel) of human mesenchymal stem cells (hMSCs) at an undifferentiated stage (i.e., $0 \mathrm{~h}$ ) and completely differentiated in mature adipocytes (i.e., 21 days upon differentiation induction) by using an induction and a maintaining mixes as reported on the timeline. hMSCs at $0 \mathrm{~h}$ and $21 \mathrm{~d}$ after adipocyte differentiation were treated for $24 \mathrm{~h}$ with conditioned medium (CM) of THP-1 macrophages (MФ) activated and not with LPS. Below are reported relative mRNA levels (qPCR) of cPPARG, PPARG 5 and the PPARG 5 /cPPARG ratio in hMSCs at $0 \mathrm{~h}$ (left panel) and in hMSCs at $21 \mathrm{~d}$ (right panel) treated with CM of MФ. hMSCs at $0 \mathrm{~h}$ or at $21 \mathrm{~d}$ treated with control medium supplemented or not with LPS were used as reference samples and PPIA as reference gene. Data are reported as mean \pm SEM of at least three independent experiments. ${ }^{*} p \leq 0.05,{ }^{* *} p \leq 0.01$ and ${ }^{* * *} p \leq 0.001$. (B) Relative mRNA quantification (qPCR) of cPPARG, PPARG 5 (left panel) and the PPARG $\Delta 5 /$ cPPARG ratio (right panel) in hMSCs at the 
undifferentiated stage treated for $24 \mathrm{~h}$ with the $\mathrm{CM}$ of primary monocyte-derived macrophages polarized in the pro-inflammatory (i.e., LPS/IFN $\gamma$-inducedM $\Phi$ ) or anti-inflammatory (IL10-induced M $\Phi$ ) type. hMSCs at $0 \mathrm{~h}$ treated with the $\mathrm{CM}$ of non-polarized primary monocyte-derived macrophages were used as a reference sample (dotted lines) and PPIA as a reference gene. Data are reported as mean \pm SEM of at least three independent experiments. ${ }^{*} p \leq 0.05,{ }^{* *} p \leq 0.01$ and ${ }^{* * *} p \leq 0.001$. (C) Relative mRNA quantification (qPCR) of cPPARG, PPARG 5 (left panel) and the PPARG $\Delta 5 / c P P A R G$ ratio (right panel) in hMSCs at $0 \mathrm{~h}$ treated for $3 \mathrm{~h}$ with 2 or $5 \mathrm{mg} / \mathrm{mL}$ of actinomycin D. hMSCs at $0 \mathrm{~h}$ treated with vehicle (i.e., DMSO) were used as a reference sample (dotted lines). PPIA was used as reference gene. Data are reported as mean \pm SEM of at least three independent experiments.

To exclude that any variation observed in PPARG transcripts' abundance is due to a different half-life, a mRNA stability assay was performed by culturing hMSCs in the presence of growing amounts of the transcription inhibitor actinomycin D (ActD). Even at higher ActD doses, a similar degradation kinetic is observed for all PPARG transcripts (Figure 2C, left panel), without any effect on their relative ratio (Figure 2C, right panel), thus excluding differential mRNA decay as a possible source of bias.

Overall, our in vitro settings reveal that a pro-inflammatory microenvironment affects both PPARG expression and splicing, providing new insights into the mechanisms underlying the link between impaired adipogenesis and inflammation in AT.

\subsection{TNFa Alters PPARG Splicing in Human Mesenchymal Stem Cells}

To identify which soluble factors released by pro-inflammatory macrophages are able to affect PPARG splicing, primary human monocytes were differentiated into macrophages and then polarized into pro-inflammatory and anti-inflammatory by LPS/IFN $\gamma$ or IL-10 treatments, respectively. In line with previous studies $[13,16,33,36]$, as shown in Figure S2A, we assessed higher levels of IL-1 $\beta$, IL- 6 , IL- 8 and TNF $\alpha$ in the conditioned media of LPS/IFN $\gamma$-induced M $\Phi$ (both vs. not polarized and IL10-induced M $\Phi$ ),. Thus, PPARG expression and splicing pattern were analyzed in human mesenchymal precursors treated with all the above-mentioned cytokines. HMSCs exposed to human recombinant IL-6 or IL-8 do not display any variation in the expression—nor in the splicing pattern—of PPARG (Figure 3A, left panel). Differently, cPPARG mRNA is significantly reduced upon treatment with TNF $\alpha$ or IL- $1 \beta$ (about $40 \%, p=0.001$, and $30 \%, p=0.0221$, reduction respectively; Figure $3 \mathrm{~A}$, left panel). Thus, it is noteworthy that only TNF $\alpha$ significantly affects PPARG splicing, increasing the PPARG $\Delta 5 /$ cPPARG ratio (1.4-fold, $p=0.0272$; Figure 3A, right panel). Similar results have been obtained by treating 3T3-L1 cells with murine recombinant TNF $\alpha$ and IL-1 $\beta$ (Figure S2B). Moreover, an high amount of TNF $\alpha$ was observed only in the conditioned media of mouse and human in vitro cultured macrophages (Figure S2C,D), able to increase PPARG $\triangle 5 /$ CPPARG ratio in adipocyte precursor cells and mature adipocytes (Figures 1C and 2A). Interestingly, a suppressive dose-dependent effect is observed on cPPARG expression - but not on PPARG $\triangle 5$ - when hMSCs are exposed to increasing TNF $\alpha$ doses (Figure 3B, left panel). Whereas the exposure to the highest TNF $\alpha$ amount $(50 \mathrm{ng} / \mathrm{mL}$ ) causes massive cell death (data not shown), TNF $\alpha$ sublethal dose $(20 \mathrm{ng} / \mathrm{mL})$ markedly increases the PPARG $\triangle 5 /$ cPPARG ratio (2.5-fold, $p=0.0123$; Figure 3B, right panel). Notably, the addition of recombinant neutralizing anti-TNF $\alpha$ antibody $(\mathrm{IgG})$ to the conditioned media of LPS-activated M $\Phi$ (THP-1) does not restore the expression of CPPARG, but reduces PPARG $\triangle 5$ levels (Figure 3C, left panel) reverting the TNF $\alpha$-induced alteration on PPARG splicing in hMSCs (Figure 3C, right panel). 
A
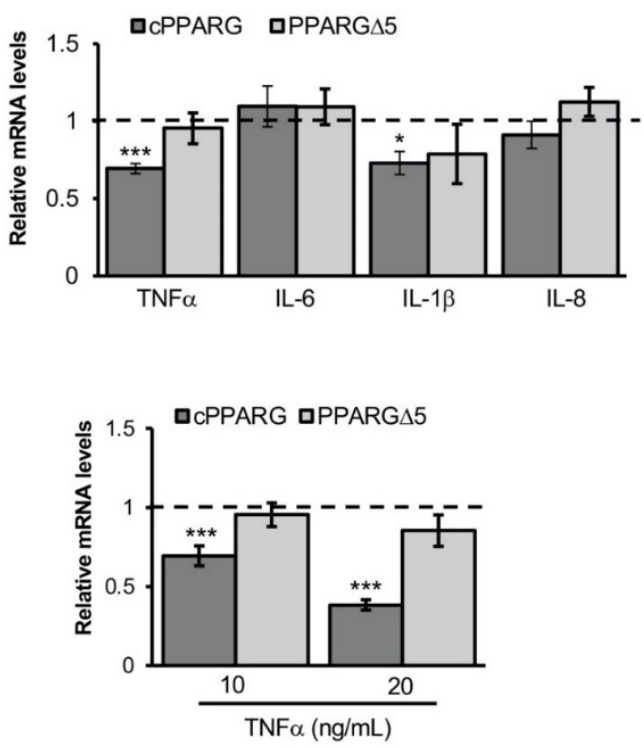

C

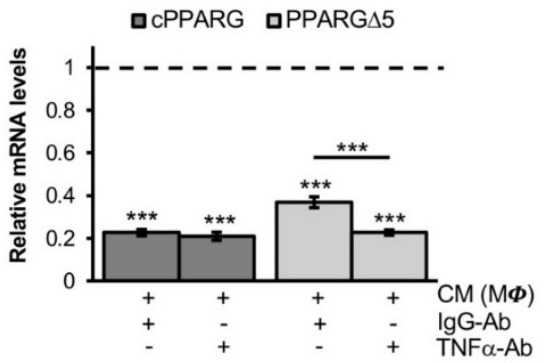

D

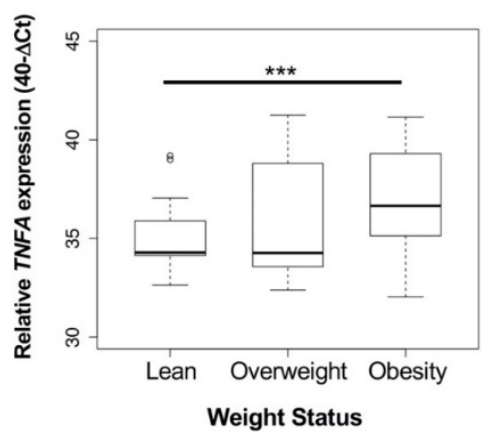

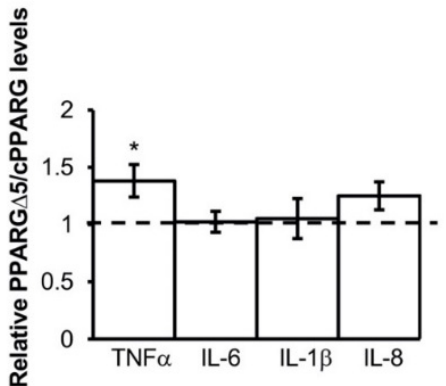
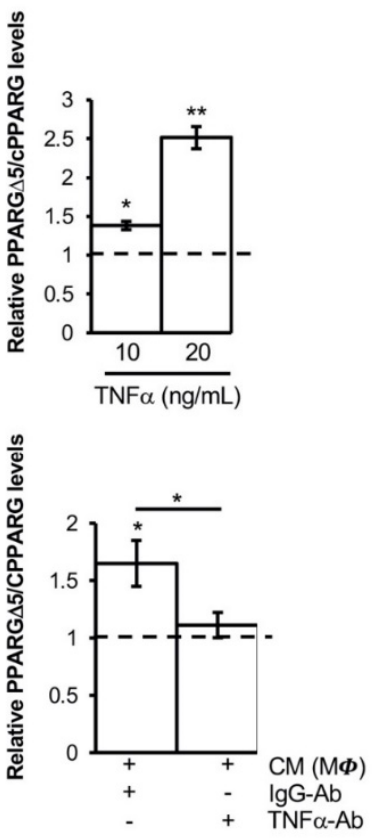

Figure 3. TNF $\alpha$ increases the PPARG $\triangle 5 / \mathrm{cPPARG}$ ratio in adipocyte precursor cells and correlates with PPARG $\triangle 5$ expression in obese patients: (A) Relative mRNA quantification (qPCR) of cPPARG, PPARG 5 (left panel) and the PPARG 5 /cPPARG ratio (right panel) in undifferentiated hMSCs treated for $24 \mathrm{~h}$ with $10 \mathrm{ng} / \mathrm{mL}$ of human recombinant TNF $\alpha$, IL-6, IL-1 $\beta$ or IL- 8 cytokines. hMSCs treated with vehicle (i.e., PBS) were used as reference samples (dotted lines) and PPIA as reference gene. Data are reported as mean \pm SEM of at least three independent experiments. ${ }^{*} p \leq 0.051$ and *** $p \leq 0.001$. (B) Relative mRNA quantification (qPCR) of cPPARG, PPARG 5 (left panel) and the PPARG 5 /cPPARG ratio (right panel) in hMSCs at undifferentiated stage treated for $24 \mathrm{~h}$ with 10 or $20 \mathrm{ng} / \mathrm{mL}$ of human recombinant TNF $\alpha$ cytokine. hMSCs treated with vehicle (i.e., PBS) were used as reference samples (dotted lines) and PPIA as reference gene. Data are reported as mean $\pm \mathrm{SEM}$ of at least three independent experiments. ${ }^{*} p \leq 0.05,{ }^{* *} p \leq 0.01$ and ${ }^{* * *} p \leq 0.001$. (C) Relative mRNA quantification (qPCR) of cPPARG, PPARG 5 (left panel) and the PPARG $\Delta 5 / c P P A R G$ ratio (right panel) in undifferentiated hMSCs treated for $24 \mathrm{~h}$ with conditioned medium (CM) of LPS-activated 
MФ (THP-1) plus $0.5 \mathrm{mg} / \mathrm{mL}$ of human neutralizing antibody against TNF $\alpha$ or anti-IgG1 Isotype. hMSCs treated with control medium supplemented with antibody against anti-IgG1 Isotype were used as reference samples (dotted lines). PPIA was used as the reference gene. Data are reported as mean \pm SEM of at least three independent experiments. ${ }^{*} p \leq 0.05$ and ${ }^{* * *} p \leq 0.001$. (D) Boxplot showing TNFA levels in three different subgroups of individuals from the German cohort, classified according to their BMI in lean $(n=14)$, overweight $(n=17)$ and obesity $(n=24)$. Data are reported as $40-\triangle \mathrm{Ct}$ value \pm DEVST. RPS23 was used as reference gene. ${ }^{* * *} p \leq 0.001$.

Moreover, to investigate ex vivo the correlation between TNF $\alpha$ and PPARG splicing alteration, we evaluated TNFA expression in the subcutaneous adipose tissue (SAT) biopsies of a subset of lean, overweight and obese individuals $(n=56)$ from a German cohort, described in our previous studies [29,30]. As expected, TNFA mRNA expression was markedly higher in the obese group (vs. lean individuals; $p=0.0018$; Figure 3D), in line with the increasing accumulation of pro-inflammatory macrophages in AT. Of note, we observed a mild positive correlation between TNFA expression and PPARG $\triangle 5$ mRNA levels $(\mathrm{r}=0.45, p=0.027$; Figure S3A) only in the SAT of obese individuals, whereas no correlation was observed between TNFA and PPARG canonical transcripts $(\mathrm{r}=0.19$, $p=0.37$; Figure S3B). These data reveal a previously unrecognized effect of TNF $\alpha$ on PPARG splicing, suggesting it as a relevant pro-inflammatory molecule able to negatively affect the transcription and splicing at the PPARG locus. Thus, although the transcriptional repression induced by TNF $\alpha$ on the PPARG gene has already been reported [21,22], our data reveal that TNF $\alpha$ does not equally affect all PPARG transcripts, determining an altered balance of canonical and dominant negative isoforms.

\subsection{TNFa Modifies PPARG Splicing through PI3K/Akt Signaling}

Since TNF $\alpha$ does not equally repress all PPARG transcripts-affecting only cPPARG levels-(Figure $3 \mathrm{~A}, \mathrm{~B}$ ) and canonical and alternative PPARG mRNAs have similar stability (Figure 2C), we hypothesized a direct effect of TNF $\alpha$ on members of the splicing machinery. In line with this hypothesis, TNF $\alpha$ is known to induce the splicing of different genes by phosphorylating multiple SR proteins [37-39]. Moreover, we previously reported the contribution of ASF2/SF2 to PPARG exon 5 skipping [29]. Therefore, we evaluated SR proteins phosphorylation in hMSCs exposed to TNF $\alpha$, observing a pronounced phosphorylation of SRp40 (alias SRSF5; Figure 4A). Otherwise, we did not detect marked ASF/SF2 phosphorylation levels. Moreover, a dose-dependent increase of pSRp40 was observed (Figure 4A). Similarly, the conditioned media collected from LPS-activated M $($ THP-1) are able to induce SRp40 phosphorylation (Figure 4B), which is reduced—but not completely abolished-by the addition of neutralizing anti-TNF $\alpha \operatorname{IgG}$ (Figure 4B). This finding suggests that other MФ-secreted pro-inflammatory factors may sustain SRp40 phosphorylation in the AT.

Furthermore, we attempted to verify how TNF $\alpha$ promotes SRp40 phosphorylation in hMSCs. Interestingly, PI3K/Akt signaling —a known target of TNF $\alpha$ [40,41] —has been reported to induce alternative splicing of PKCbII gene via SRp40 phosphorylation [42]. Hence, we hypothesized that the stimulation of the PI3K/Akt pathway may mediate the effects of TNF $\alpha$ on SRp40. According to this hypothesis, pAkt levels (Ser473) significantly increase upon TNF $\alpha$ exposure (Figure $4 \mathrm{C}$ ). Moreover, the addition of neutralizing TNF $\alpha$ antibody to the conditioned media of LPS-activated M $\Phi$ (THP-1) is able to reduce Akt phosphorylation (Figure 4D). Accordingly, PI3K inhibition - induced by cell treatment with wortmannin - blocks Akt phosphorylation and in turn TNF $\alpha$-mediated phosphorylation of SRp40 (Figures 4E and S4A). 
A
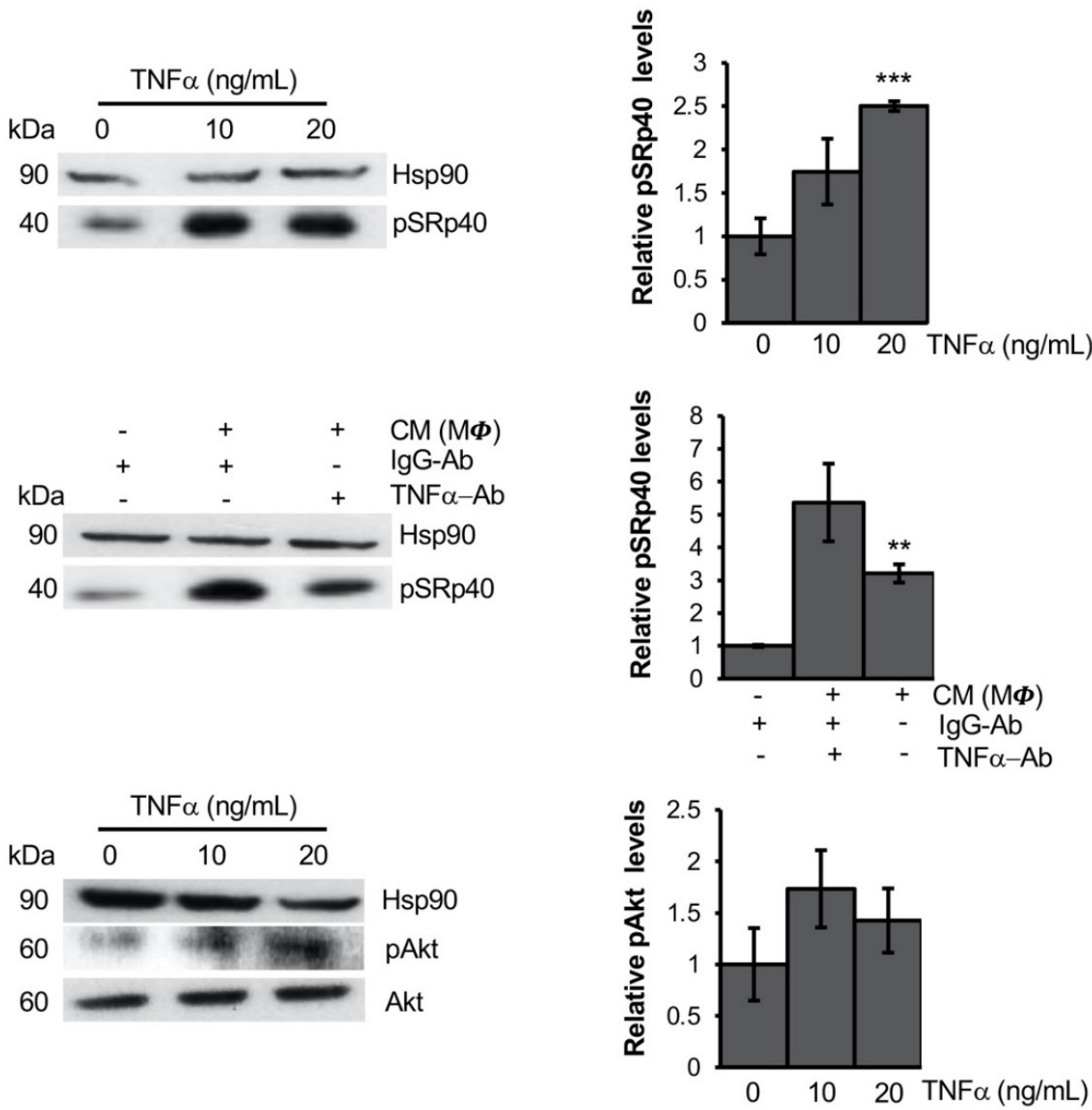

D
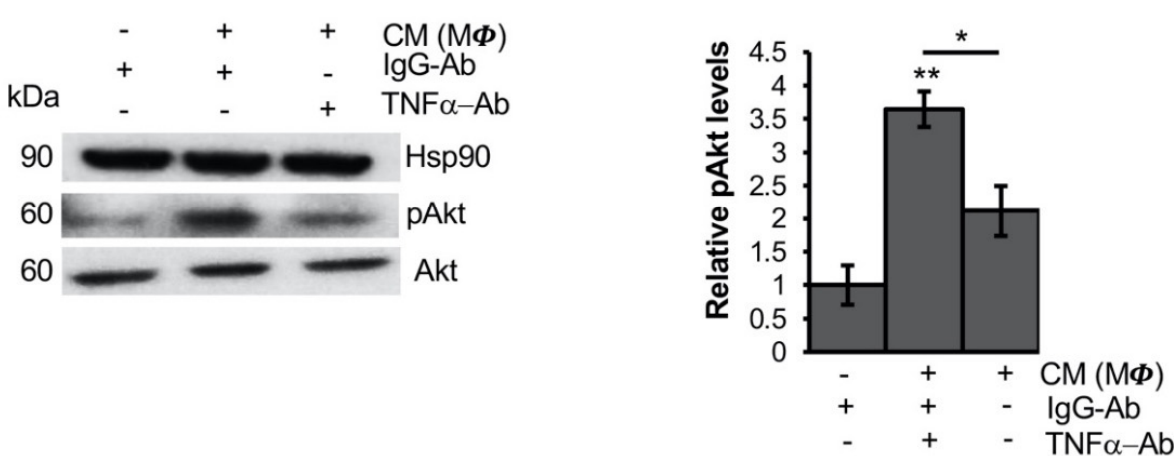

E
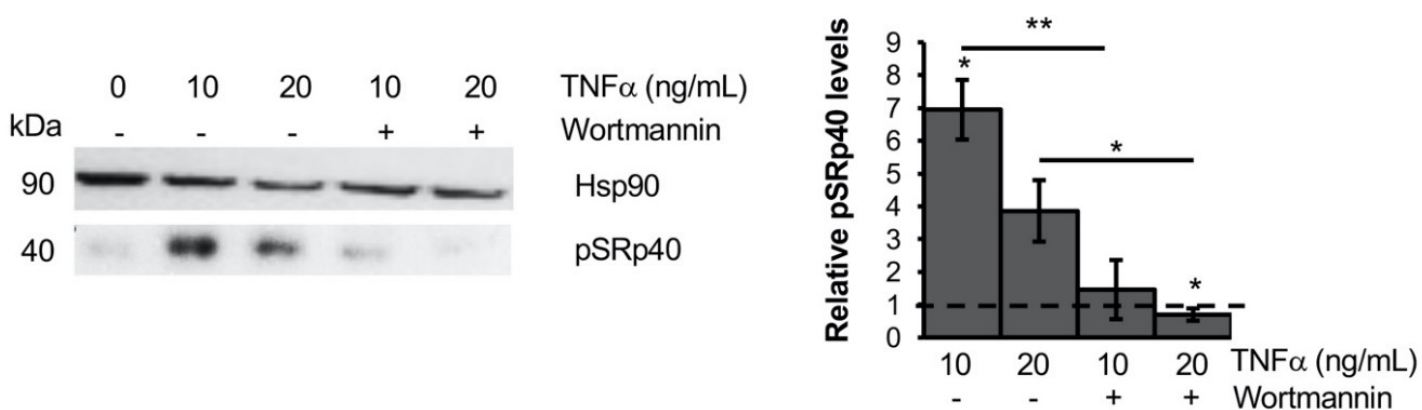

Figure 4. TNF $\alpha$ increases SRp40 phosphorylation through AKT: (A) Representative autoradiograph of Western blot analysis (left panel) of SRp40 phosphorylation (i.e., pSRp40) levels in hMSCSc at T $=0 \mathrm{~h}$ 
treated for $30 \mathrm{~min}$ with 10 or $20 \mathrm{ng} / \mathrm{mL}$ of TNF $\alpha$ cytokine or with vehicle (i.e., PBS). Hsp90 was used as a loading control. Bar graphs (right panel) report relative pSRp40 levels normalized on Hsp90 expression (pixel density analysis of Western blots). Data are representative of the mean \pm SEM of three independent experiments. ${ }^{* * *} p \leq 0.001$. (B) Representative Western blot of pSRp40 (left panel) on lysates from undifferentiated hMSCs treated for $24 \mathrm{~h}$ with conditioned medium (CM) of LPS-activated MФ (THP-1) or control medium plus $0.5 \mathrm{mg} / \mathrm{mL}$ of human neutralizing antibody against $\mathrm{TNF} \alpha$ or anti-IgG1 Isotype. Hsp90 was used as loading control. Bar graphs (right panel) report relative pSRp40 levels normalized on Hsp90 expression (pixel density analysis of Western blots). Data are representative of the mean \pm SEM of three independent experiments. ${ }^{* *} p \leq 0.01$. (C) Representative immunoblotting of Akt phosphorylation (i.e., pAkt) and total Akt levels (right panel) in hMSCSc at $\mathrm{T}=0 \mathrm{~h}$ treated for $30 \mathrm{~min}$ with 10 or $20 \mathrm{ng} / \mathrm{mL}$ of TNF $\alpha$ cytokine or with vehicle (i.e., PBS). Hsp90 was used as loading control. Bar graphs (right panel) report relative pAkt levels normalized on Hsp90 and total Akt expression (pixel density analysis of Western blots). Data are representative of the mean \pm SEM of three independent experiments. (D) Representative autoradiograph of Western blot analysis (left panel) of pAkt and total Akt levels in undifferentiated hMScs treated for $24 \mathrm{~h}$ with the CM of LPS-activated MФ (THP-1) or control medium plus $0.5 \mathrm{mg} / \mathrm{mL}$ of human neutralizing antibody against $\mathrm{TNF} \alpha$ or anti-IgG1 Isotype. Hsp90 was used as loading control. Bar graphs (right panel) report relative pAkt levels normalized on Hsp90 and total Akt expression (pixel density analysis of Western blots). Data are representative of the mean $\pm \mathrm{SEM}$ of at least three independent experiments. ${ }^{*} p \leq 0.05$ and ${ }^{* *} p \leq 0.01$. (E) Representative immunoblotting of pSRp40 (left panel) in undifferentiated hMSCs treated with Wortmannin or vehicle (i.e., DMSO) in combination and not with 10 or $20 \mathrm{ng} / \mathrm{mL}$ of TNF $\alpha$ cytokine. Hsp90 was used as loading control. Bar graphs (right panel) report relative pSRp40 levels normalized on Hsp90 expression (pixel density analysis of Western blots). Data are representative of the mean \pm SEM of at least three independent experiments. ${ }^{*} p \leq 0.05$ and ${ }^{* *} p \leq 0.01$.

In light of these data, we first evaluated the impact of SRp40 silencing on TNF $\alpha$-mediated PPARG splicing in hMSCs. Surprisingly, SRSF5 knockdown (Figures 5A and S4B,C), in cells treated with TNF $\alpha$ or the conditioned media of LPS-activated MФ (THP-1), significantly increases PPARG exon 5 skipping and, in turn, the PPARG 5 /cPPARG ratio. This unexpected result suggests that $S R p 40$ is required to balance the inclusion/exclusion rate of PPARG exon 5 in the presence of inflammatory stimuli.

Moreover, it is documented that different SR proteins may cooperatively work to regulate the alternative splicing [43-45]. Hence, to explore whether other SR proteins may account for PPARG exon 5 skipping, we simultaneously blocked the activity of multiple SR proteins, including SRp40. TNF $\alpha$-treated hMSCs were exposed to drugs (i.e., KHCB19 and SRPIN340) inhibiting two distinct classes of protein kinases-i.e., Cyclin-dependent kinases 1-4 (Clk) and Serine/arginine rich protein kinases 1-2 (Srpk)—which phosphorylate (and activate) SR proteins. Moreover, using wortmannin, we blocked PI3K/Akt signaling, responsible for Clk- and Srpk-mediated SR phosphorylation [44]. Interestingly, the inhibition of Clk by KHCB19 in TNF $\alpha$-treated hMSCs, induces a strong increase of PPARG $\triangle 5$ levels and of PPARG $\Delta$ /cPPARG ratio (Figure 5B,C), likewise the inhibition of Srpk1 and Srpk2 proteins by SRPIN340 (Figure S4D). Similarly, PI3K inhibition by wortmannin in presence of TNF $\alpha$ was sufficient to increase the PPARG $\Delta 5 / c$ PPARG ratio (Figure 5D).

Thus, these results further support the role of PI3K/Akt signaling in linking inflammation to PPARG splicing and suggest that the inhibition of SR proteins facilitates the activity of other competing splicing factors—such as heterogeneous nuclear ribonucleoproteins (hnRNPs) [46-48]—in the modulation of PPARG exon 5 inclusion/exclusion. 
A
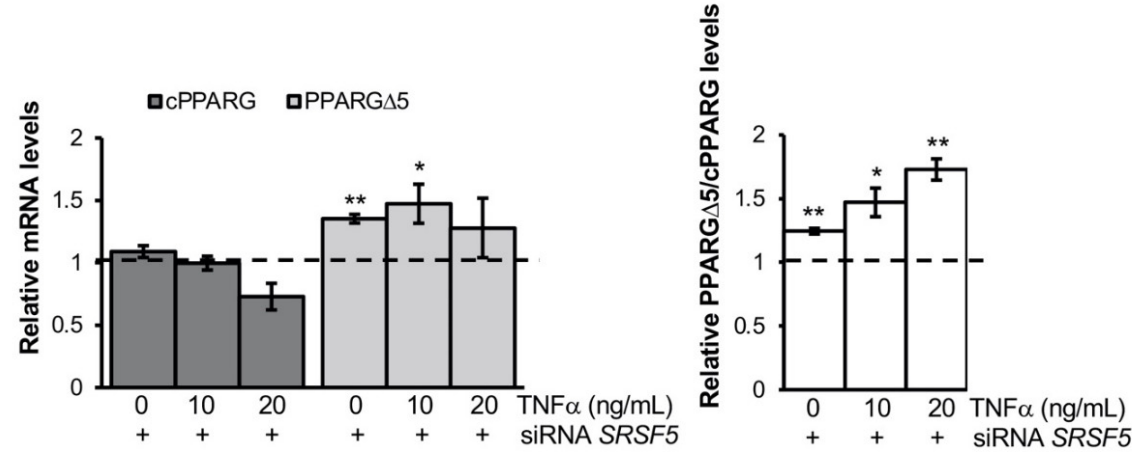

B

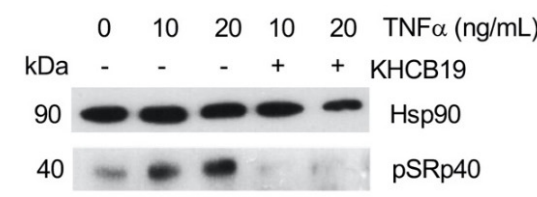

C
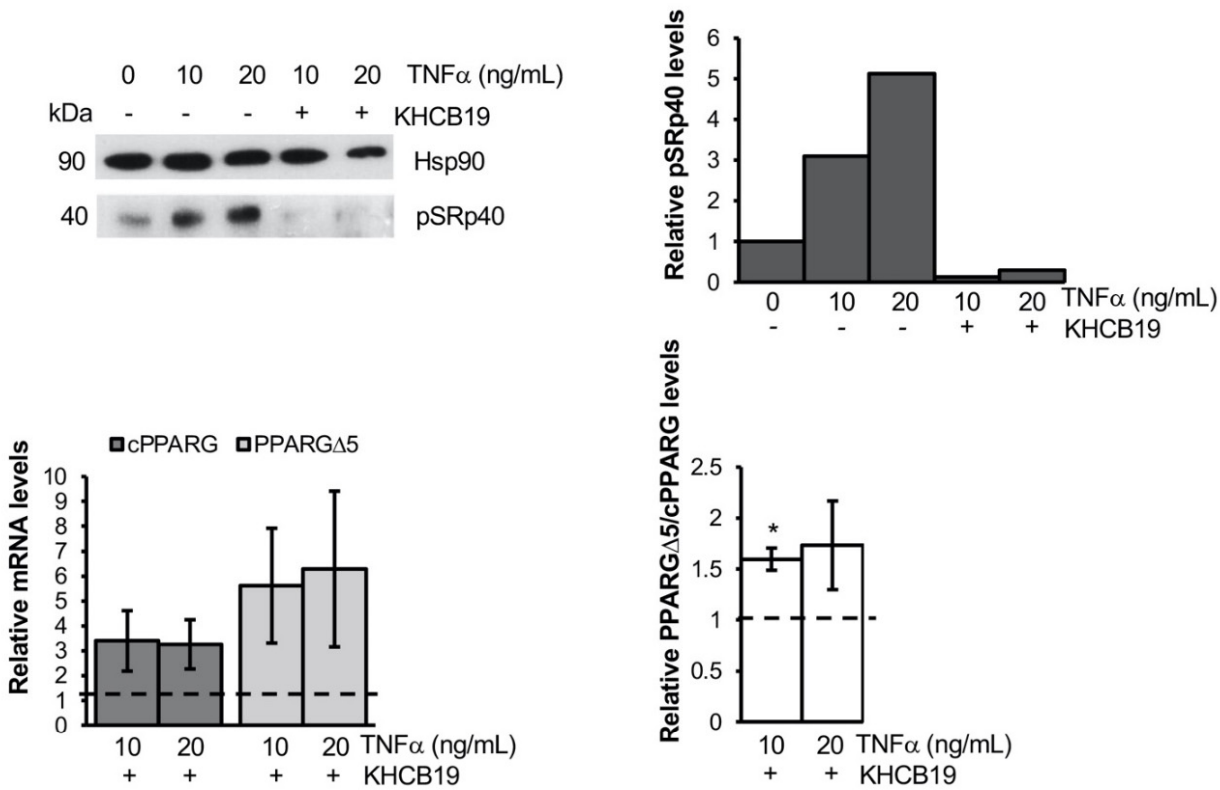

D
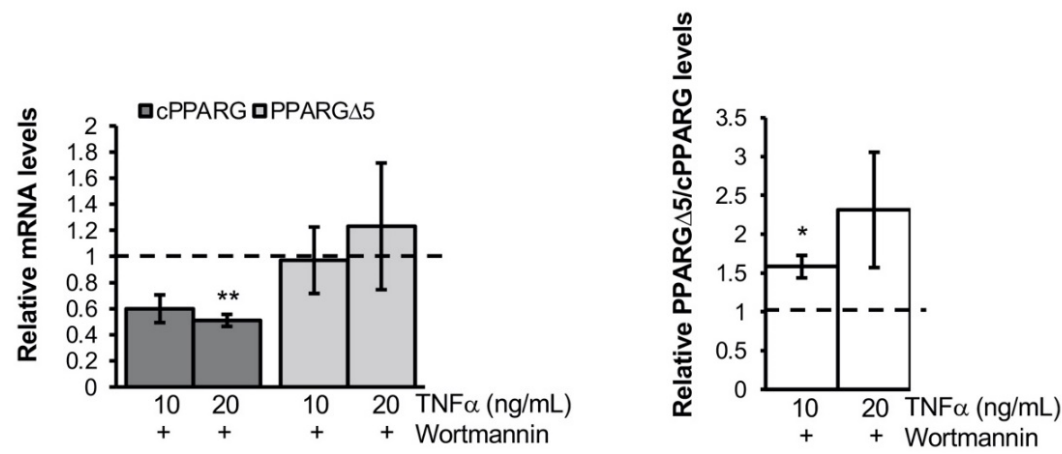

Figure 5. SRp40 is involved in the PPARG splicing modulation induced by TNF $\alpha$ : (A) Relative mRNA quantification (qPCR) of cPPARG, PPARG 5 (left panel) and the PPARG $\Delta 5 /$ cPPARG ratio (right panel) in hMSCs at the undifferentiated stage knock out for SRSF5 and treated for $24 \mathrm{~h}$ with 0,10 or 20 $\mathrm{ng} / \mathrm{mL}$ of human recombinant TNF $\alpha$ cytokine. hMSCs at $0 \mathrm{~h}$ transfected scrambled and treated for $24 \mathrm{~h}$ with 0,10 or $20 \mathrm{ng} / \mathrm{mL}$ of human recombinant TNF $\alpha$ cytokine were used as reference samples (dotted lines). PPIA was used as the reference gene. Data are reported as mean \pm SEM of at least three independent experiments. ${ }^{*} p \leq 0.05$ and ${ }^{* *} p \leq 0.01$. (B) Western blot of SRp40 phosphorylation (i.e., pSRp40; left panel) levels in hMSCs at $\mathrm{T}=0 \mathrm{~h}$ treated with wortmannin or vehicle (i.e., DMSO) in combination and not with 10 or $20 \mathrm{ng} / \mathrm{mL}$ of TNF $\alpha$ cytokine. Hsp90 was used as loading control. Bar graphs (right panel) report relative pSRp40 levels normalized on Hsp90 expression (pixel density analysis of Western blot). (C) Relative mRNA quantification (qPCR) of cPPARG, PPARG 5 (left panel) 
and the PPARG $\triangle 5 /$ CPPARG ratio (right panel) in hMSCs at the undifferentiated stage treated with 10 or $20 \mathrm{ng} / \mathrm{mL}$ of human recombinant TNF $\alpha$ cytokine in combination or not with KHCB19 inhibitor. hMSCs at $0 \mathrm{~h}$ treated for $24 \mathrm{~h}$ with 10 or $20 \mathrm{ng} / \mathrm{mL}$ of human recombinant TNF $\alpha$ cytokine and with vehicle (i.e., DMSO) were used as reference samples (dotted lines). PPIA was used as the reference gene. Data are reported as mean \pm SEM of at least three independent experiments. * $p \leq 0.05$. (D) Relative mRNA quantification (qPCR) of cPPARG, PPARG 5 (left panel) and the PPARG 5 /cPPARG ratio (right panel) in hMSCs at the undifferentiated stage treated with 10 or $20 \mathrm{ng} / \mathrm{mL}$ of human recombinant TNF $\alpha$ cytokine and with or without Wortmannin inhibitor. hMSCs at $0 \mathrm{~h}$ treated for $24 \mathrm{~h}$ with 10 or $20 \mathrm{ng} / \mathrm{mL}$ of human recombinant TNF $\alpha$ cytokine and with vehicle (i.e., DMSO) were used as reference samples (dotted lines). PPIA was used as the reference gene. Data are reported as mean $\pm \mathrm{SEM}$ of at least three independent experiments. ${ }^{*} p \leq 0.05$ and ${ }^{* *} p \leq 0.01$.

\section{Discussion}

Insulin resistance in individuals with hypertrophic obesity is causally associated with low-grade chronic inflammation, characterized by the infiltration of T cells, macrophages and other immune cells [4-10]. The release of cytokines and chemokines by pro-inflammatory and metabolically activated macrophages $[12,14,15]$ has a negative impact on the expression and activity of PPAR $\gamma$ [19-22]. This nuclear receptor has a well-recognized central role in differentiating new insulin-sensitive adipocytes, in keeping the metabolic homeostasis of adipose tissue, in repressing inflammatory genes (e.g., TNF $\alpha$, iNOS, MMP9) [23-28,49] and in dictating monocyte polarization toward an anti-inflammatory phenotype [50-52]. Hence, the repressing effect induced by the inflammation on PPAR $\gamma$ generates a selfsustained vicious cycle, contributing to the impairment of neo-adipogenesis, which in turn promotes adipocyte hypertrophy, as well as local and global inflammation [12,18]. We previously described a marked overexpression of the dominant-negative isoform of $\operatorname{PPAR} \gamma, \operatorname{PPAR} \gamma \Delta 5$, in the AT of obese/diabetic patients and its ability to impair adipocyte differentiation and PPAR $\gamma$ activity in hypertrophic adipocytes [29,30]. Moreover, the increased PPARG 5 /cPPARG ratio in SAT enriched of large adipocytes, as well as in our recently generated in vitro model of human hypertrophic-like adipocytes [30], further encouraged us to investigate the putative contribution of pro-inflammatory factors-highly secreted in hypertrophic AT-to the unbalance of PPARG isoforms.

Herein, we aimed to dissect the impact of inflammatory stimuli on PPARG expression and splicing, considering that the relevance of the latter has been often underestimated. The identification, for the first time, that inflammatory factors, other than repressing PPARG expression can modulate-in vitro and in vivo-its splicing pattern, adds an interesting piece to the puzzling regulation of PPARG. In this regard, our results provide evidence of a marked increase of the Pparg $\Delta 5 / \mathrm{cPparg}$ ratio-paralleled by the repression of Ppargregulated adipocyte markers-in the epididymal fat of LPS-treated mice, as well as in murine and human adipocytes exposed to macrophages-secreted pro-inflammatory factors. A similar effect on PPARG splicing is also observed in human mesenchymal stem cells, in which we recently described a role for PPARG $\triangle 5$ in reducing their adipogenic capacity [29]. Taken together, our data provide an intriguing insight in the molecular mechanisms through which the proinflammatory microenvironment contributes to the impaired neo-adipogenesis in hypertrophic AT, suggesting for PPARG splicing a role as a hub. The increased PPARG $\triangle 5$ /cPPARG ratio in the SAT of overweight/obese individuals [29] and in lipid-engulfed adipocytes [30] further support this hypothesis. However, we cannot discern the relative contributions of functional isoforms, whose levels are reduced, and of increased dominant negative isoforms to the impairment of PPAR $\gamma$ activity leading to a diminished adipogenic differentiation.

Moreover, in line with the suggested role of $\mathrm{TNF} \alpha$ as a key mediator of the effects induced by inflammation on preadipocytes and adipocyte differentiation [53,54], herein we reported TNF $\alpha$ - known to inhibit PPAR $\gamma$ activity through distinct mechanisms [21,22]—as a major pro-inflammatory cytokine able to alter PPARG splicing pattern. Ex vivo analyses on SAT biopsies revealed higher TNFA expression and a positive correlation with PPARG 5 levels 
only in obese (but not in lean) individuals, further supporting also in human hypertrophic adipocytes the link between inflammation and PPARG splicing alteration. Interestingly, the finding that canonical and alternative PPARG transcripts have the same half-life but respond differently to $\mathrm{TNF} \alpha$, as well as to the conditioned media of proinflammatory macrophages, supports a direct effect of inflammation on the splicing machinery. Of note, the alteration of spliceosome machinery due to altered levels of phosphorylated proteins involved in mRNA splicing has been recently reported even in the context of obesity and T2D [55-57]. Moreover, TNF $\alpha$ is known to dynamically modulate the inclusion/exclusion rate of alternative exons by enhancing the phosphorylation of multiple SR proteins [37-39]. In our experimental settings-i.e., in hMSCs exposed to M $\Phi$-secreted pro-inflammatory factors-we found a TNF $\alpha$-mediated increase of SRp40 phosphorylation, suggesting a still unexplored role for this splicing factor in PPARG exon 5 inclusion/exclusion. However, as we did not definitely establish the exact role of SRp40 in PPARG splicing, we cannot exclude that multiple SR proteins may cooperate in the modulation of PPARG exon 5 inclusion/exclusion balance and in turn to the generation of the truncated PPAR $\gamma$ isoform.

The finding that $M \Phi$-secreted TNF $\alpha$ impairs PPAR $\gamma$ functionality by promoting the generation of dominant negative isoforms over canonical ones has relevance also from a therapeutic perspective. Indeed, the recently developed anti-inflammatory drugs, which specifically targeting pro-inflammatory $M \Phi$, revealed to be very promising to ameliorate obesity-related inflammation and metabolic dysfunctions [58]. Moreover, the mechanisms underlying polarization of $\mathrm{M} \Phi$ into pro-inflammatory and metabolically activated cellsrather than in anti-inflammatory $\mathrm{M} \Phi$-in the AT of obese patients $[12,14,15]$ remain to be elucidated. Of note, human monocytes/macrophages express PPAR $\gamma$ dominant negative isoforms $[29,59]$. Hence, given the key role of PPAR $\gamma$ in monocyte polarization, we might speculate that autocrine (or paracrine) signaling in a hypertrophic AT microenvironment may affect PPARG transcripts abundance in AT-resident $\mathrm{M} \Phi$, contributing to disease etiology.

In conclusion, our results demonstrate a novel mechanism through which inflammation impairs PPAR $\gamma$ activity in the AT. The imbalance among functional and dominant negative PPARG transcripts is likely to contribute to establishing healthy and unhealthy AT under positive energy intake. These data further indicate the relevance to target inflammation in adipose tissue of patients with hypertrophic obesity to minimize the detrimental effects that pro-inflammatory molecules have on PPAR $\gamma$ functionality in this tissue.

Supplementary Materials: The following are available online at https:/ / www.mdpi.com/article/ 10.3390/cells11010042/s1, Figure S1: Conditioned media from mouse macrophages modulate the expression of cPparg and Pparg $\Delta 5$ transcripts. Figure S2: Cytokines secretions by ex vivo and in vitro macrophages and their effects on Pparg splicing in 3T3-L1 cells. Figure S3: TNFA mRNA levels positive correlate with PPARG $\triangle 5$ levels in obese individuals. Figure S4: Inflammatory stimuli modulate PPARG splicing through SRp40 phosphorylation. Table S1: List of primers sequence of gene analyzed by qPCR.

Author Contributions: V.C. and S.C. designed the experiments; S.C., M.A. and I.M. performed experiments; V.C., S.C. and M.A. analyzed data; J.-F.T., S.G.-P. and M.C. conducted in vivo experiments; P.I. and D.M. carried out differentiation and polarization of human primary macrophages; M.B. provided patient biopsy specimens and was involved in interpretation of ex vivo data. V.C. and S.C. processed data; V.C. and S.C. wrote the paper, with significant contributions from M.A.; V.C. and A.C. supervised all the experiments and coordinated the interactions among the collaborators. All the authors contributed to data interpretation and discussion, edited and approved the final manuscript. All authors have read and agreed to the published version of the manuscript.

Funding: This work was funded by PON Ricerca e Innovazione 2014-2020, PON Ars01_01270 “Innovative Device For SHAping the Risk of Diabetes" (IDF SHARID) to V.C. and EFSD/Boehringer Ingelheim European Research Programme in Microvascular Complications of Diabetes to A.C. Theresearch contract of S.C. and publication fees were in part supported by Project SATIN-POR Campania FESR 2014/2020, funded to V.C. 
Institutional Review Board Statement: The study was conducted according to the Principles of Laboratory Animal Care (NIH publication no. 85-23, revised 1985) and the European Union guidelines on animal laboratory care. All procedures were approved by Animal Care Committee of the Faculty of Medicine of the Nice-Sophia Antipolis University, Nice, France, and the French ministry of national education (\#05116.02 and \#201505\&9143792_v2). The study has been reviewed and approved by the ethics committee of Leipzig University, Germany (approval numbers: 159-12-21052012 and 017-1223012012) and carried out in accordance with the Declaration of Helsinki, the Bioethics Convention (Oviedo) and the EU Directive on Clinical Trials (Directive 2001/20/EC).

Informed Consent Statement: Informed consent was obtained from all subjects involved in the study. Acknowledgments: We express our gratitude to Caterina Perfetto for helping with experimental settings.

Conflicts of Interest: The authors declare no conflict of interests.

\section{References}

1. Blüher, M. Metabolically Healthy Obesity. Endocr. Rev. 2020, 41, 405-420. [CrossRef] [PubMed]

2. Bray, G.A.; Kim, K.K.; Wilding, J.P.H.; World Obesity Federation. Obesity: A chronic relapsing progressive disease process. A position statement of the World Obesity Federation. Obes. Rev. 2017, 18, 715-723. [CrossRef]

3. Lumeng, C.N.; Saltiel, A. Inflammatory links between obesity and metabolic disease. J. Clin. Investig. 2011, 121, 2111-2117. [CrossRef] [PubMed]

4. Olefsky, J.M.; Glass, C.K. Macrophages, Inflammation, and Insulin Resistance. Annu. Rev. Physiol. 2010, 72, 219-246. [CrossRef] [PubMed]

5. Hotamisligil, G.S. Inflammation and metabolic disorders. Nature 2006, 444, 860-867. [CrossRef] [PubMed]

6. Reilly, S.M.; Saltiel, A.R. Adapting to obesity with adipose tissue inflammation. Nat. Rev. Endocrinol. 2017, 13, 633-643. [CrossRef] [PubMed]

7. $\quad$ Kanda, H.; Tateya, S.; Tamori, Y.; Kotani, K.; Hiasa, K.I.; Kitazawa, R.; Kitazawa, S.; Miyachi, H.; Maeda, S.; Egashira, K.; et al. MCP-1 contributes to macrophageinfiltration into adipose tissue, insulin resistance, and hepatic steatosis in obesity. J. Clin. Investig. 2006, 116, 1494-1505. [CrossRef] [PubMed]

8. Cinti, S.; Mitchell, G.; Barbatelli, G.; Murano, I.; Ceresi, E.; Faloia, E.; Wang, S.; Fortier, M.; Greenberg, A.S.; Obin, M.S. Adipocyte death defines macrophage localization and function in adipose tissue of obese mice and humans. J. Lipid Res. 2005, 46, 2347-2355. [CrossRef] [PubMed]

9. Wellen, K.E.; Hotamisligil, G.S. Obesity-induced inflammatory changes in adipose tissue. J. Clin. Investig. 2003, 112, 1785-1788. [CrossRef]

10. Wensveen, F.; Valentić, S.; Šestan, M.; Wensveen, T.T.; Polić, B. The "Big Bang" in obese fat: Events initiating obesity-induced adipose tissue inflammation. Eur. J. Immunol. 2015, 45, 2446-2456. [CrossRef] [PubMed]

11. Russo, L.; Muir, L.; Geletka, L.; Delproposto, J.; Baker, N.; Flesher, C.; O’Rourke, R.; Lumeng, C.N. Cholesterol 25-hydroxylase $(\mathrm{CH} 25 \mathrm{H})$ as a promoter of adipose tissue inflammation in obesity and diabetes. Mol. Metab. 2020, 39, 100983. [CrossRef]

12. Gustafson, B.; Gogg, S.; Hedjazifar, S.; Jenndahl, L.; Hammarstedt, A.; Smith, U. Inflammation and impaired adipogenesis in hypertrophic obesity in man. Am. J. Physiol. Metab. 2009, 297, E999-E1003. [CrossRef] [PubMed]

13. Suganami, T.; Nishida, J.; Ogawa, Y. A paracrine loop between adipocytes and macrophages aggravates inflammatory changes: Role of free fatty acids and tumor necrosis factor alpha. Arterioscler. Thromb. Vasc. Biol. 2005, 25, 2062-2068. [CrossRef]

14. Weisberg, S.P.; McCann, D.; Desai, M.; Rosenbaum, M.; Leibel, R.L.; Ferrante, A.W., Jr. Obesity is associated with macrophage accumulation in adipose tissue. J. Clin. Investig. 2003, 12, 1796-1808. [CrossRef]

15. Xu, H.; Barnes, G.T.; Yang, Q.; Tan, G.; Yang, D.; Chou, C.J.; Sole, J.; Nichols, A.; Ross, J.S.; Tartaglia, L.A.; et al. Chronic inflammation in fat plays a crucial role in the de-velopment of obesity-related insulin resistance. J. Clin. Investig. 2003, 12, 1821-1830. [CrossRef]

16. Lumeng, C.N.; Deyoung, S.M.; Saltiel, A.R. Macrophages block insulin action in adipocytes by altering expression of signal-ing and glucose transport proteins. Am. J. Physiol. Endocrinol. Metab. 2007, 292, E166-E174. [CrossRef] [PubMed]

17. Armoni, M.; Harel, C.; Karnieli, E. Transcriptional regulation of the GLUT4 gene: From PPAR-gamma and FOXO1 to FFA and inflammation. Trends Endocrinol. Metab. 2007, 18, 100-107. [CrossRef] [PubMed]

18. Liu, L.F.; Craig, C.; Tolentino, L.L.; Choi, O.; Morton, J.; Rivas, H.; Cushman, S.W.; Engleman, E.G.; McLaughlin, T. Adipose tissue macrophages impair preadipocyte differentiation in humans. PLoS ONE 2017, 12, e0170728. [CrossRef]

19. Yin, R.; Fang, L.; Li, Y.; Xue, P.; Li, Y.; Guan, Y.; Chang, Y.; Chen, C.; Wang, N. Pro-inflammatory Macrophages suppress PPAR $\gamma$ activity in Adipocytes via S-nitrosylation. Free Radic. Biol. Med. 2015, 89, 895-905. [CrossRef]

20. Isakson, P.; Hammarstedt, A.; Gustafson, B.; Smith, U. Impaired Preadipocyte Differentiation in Human Abdominal Obesity: Role of Wnt, Tumor Necrosis Factor-, and Inflammation. Diabetes 2009, 58, 1550-1557. [CrossRef] [PubMed]

21. Ruan, H.; Hacohen, N.; Golub, T.R.; Van Parijs, L.; Lodish, H.F. Tumor Necrosis Factor- $\alpha$ Suppresses Adipocyte-Specific Genes and Activates Expression of Preadipocyte Genes in 3T3-L1 Adipocytes: Nuclear Factor- $k$ B Activation by TNF- $\alpha$ Is Obligatory. Diabetes 2002, 51, 1319-1336. [CrossRef] [PubMed] 
22. Zhang, B.; Berger, J.; Hu, E.; Szalkowski, D.; White-Carrington, S.; Spiegelman, B.M.; Moller, D.E. Negative regulation of peroxisome proliferator-activated receptor-gamma gene expression contributes to the antiadipogenic effects of tumor necrosis factor-alpha. Mol. Endocrinol. 1996, 10, 1457-1466. [CrossRef] [PubMed]

23. Lefterova, M.I.; Haakonsson, A.K.; Lazar, M.A.; Mandrup, S. PPAR $\gamma$ and the global map of adipogenesis and beyond. Trends Endocrinol. Metab. 2014, 25, 293-302. [CrossRef]

24. Ahmadian, M.; Suh, J.M.; Hah, N.; Liddle, C.; Atkins, A.R.; Downes, M.; Evans, R.M. PPAR $\gamma$ signaling and metabolism: The good, the bad and the future. Nat. Med. 2013, 19, 557-566. [CrossRef] [PubMed]

25. Rosen, E.D.; MacDougald, O.A. Adipocyte differentiation from the inside out. Nat. Rev. Mol. Cell Biol. 2006, 7, 885-896. [CrossRef]

26. Lehrke, M.; Lazar, M.A. The many faces of PPARgamma. Cell. Rev. 2005, 123, 993-999. [CrossRef]

27. Imai, T.; Takakuwa, R.; Marchand, S.; Dentz, E.; Bornert, J.-M.; Messaddeq, N.; Wendling, O.; Mark, M.; Desvergne, B.; Wahli, W.; et al. Peroxisome proliferator-activated receptor is required in mature white and brown adipocytes for their survival in the mouse. Proc. Natl. Acad. Sci. USA 2004, 101, 4543-4547. [CrossRef] [PubMed]

28. Tontonoz, P.; Hu, E.; Spiegelman, B.M. Stimulation of adipogenesis in fibroblasts by PPAR gamma 2, a lipid-activated transcription factor. Cell 1995, 79, 1147-1156. [CrossRef]

29. Aprile, M.; Cataldi, S.; Ambrosio, M.R.; D’Esposito, V.; Lim, K.; Dietrich, A.; Blüher, M.; Savage, D.B.; Formisano, P.; Ciccodicola, A.; et al. PPAR $\gamma \Delta 5$, a Naturally Occurring Dominant-Negative Splice Isoform, Impairs PPAR $\gamma$ Function and Adipocyte Differentiation. Cell Rep. 2018, 25, 1577-1592.e6. [CrossRef] [PubMed]

30. Aprile, M.; Cataldi, S.; Perfetto, C.; Ambrosio, M.R.; Italiani, P.; Tatè, R.; Blüher, M.; Ciccodicola, A.; Costa, V. In Vitro-Generated Hypertrophic-Like Adipocytes Displaying PPARG Isoforms Unbalance Recapitulate Adipocyte Dysfunctions In Vivo. Cells 2020, 9, 1284. [CrossRef]

31. Keller, M.; Hopp, L.; Liu, X.; Wohland, T.; Rohde, K.; Cancello, R.; Klös, M.; Bacos, K.; Kern, M.; Eichelmann, F.; et al. Genomewide DNA promoter methylation and transcriptome analysis in human adipose tissue unravels novel candidate genes for obesity. Mol. Metab. 2016, 6, 86-100. [CrossRef] [PubMed]

32. Guiu-Jurado, E.; Unthan, M.; Böhler, N.; Kern, M.; Landgraf, K.; Dietrich, A.; Schleinitz, D.; Ruschke, K.; Klöting, N.; Faßhauer, M.; et al. Bone morphogenetic protein 2 (BMP2) may contribute to partition of energy storage into visceral and subcutaneous fat depots. Obesity 2016, 24, 2092-2100. [CrossRef] [PubMed]

33. Pastor, F.; Dumas, K.; Barthélémy, M.-A.; Regazzetti, C.; Druelle, N.; Peraldi, P.; Cormont, M.; Tanti, J.-F.; Giorgetti-Peraldi, S. Implication of REDD1 in the activation of inflammatory pathways. Sci. Rep. 2017, 7, 7023. [CrossRef] [PubMed]

34. Appari, M.; Channon, K.M.; McNeill, E. Metabolic Regulation of Adipose Tissue Macrophage Function in Obesity and Diabetes. Antioxid. Redox Signal. 2018, 29, 297-312. [CrossRef] [PubMed]

35. Nawaz, A.; Tobe, K. M2-like macrophages serve as a niche for adipocyte progenitors in adipose tissue. J. Diabetes Investig. 2019, 10, 1394-1400. [CrossRef] [PubMed]

36. Arango Duque, G.; Descoteaux, A. Macrophage Cytokines: Involvement in Immunity and Infectious Diseases. Front. Immunol. 2014, 5, 491. [CrossRef] [PubMed]

37. Batson, J.; Toop, H.D.; Redondo, C.; Babaei-Jadidi, R.; Chaikuad, A.; Wearmouth, S.; Gibbons, B.; Allen, C.; Tallant, C.; Zhang, J.; et al. Development of Potent, Selective SRPK1 Inhibitors as Potential Topical Therapeutics for Neovascular Eye Disease. ACS Chem. Biol. 2017, 12, 825-832. [CrossRef]

38. Nowak, D.G.; Amin, E.M.; Rennel, E.S.; Hoareau-Aveilla, C.; Gammons, M.; Damodoran, G.; Hagiwara, M.; Harper, S.J.; Woolard, J.; Ladomery, M.R.; et al. Regulation of Vascular Endothelial Growth Factor (VEGF) Splicing from Pro-angiogenic to Anti-angiogenic Isoforms: A novel therapeutic strategy for angiogenesis. J. Biol. Chem. 2010, 285, 5532-5540. [CrossRef]

39. Nowak, D.G.; Woolard, J.; Amin, E.M.; Konopatskaya, O.; Saleem, M.A.; Churchill, A.J.; Ladomery, M.R.; Harper, S.J.; Bates, D.O. Expression of pro- and anti-angiogenic isoforms of VEGF is differentially regulated by splicing and growth factors. J. Cell Sci. 2008, 121, 3487-3495. [CrossRef]

40. Zhou, Z.; Gengaro, P.; Wang, W.; Wang, X.-Q.; Li, C.; Faubel, S.; Rivard, C.; Schrier, R.W. Role of NF-kB and PI 3-kinase/Akt in TNF- $\alpha$-induced cytotoxicity in microvascular endothelial cells. Am. J. Physiol. Physiol. 2008, 295, F932-F941. [CrossRef]

41. Faurschou, A.; Gniadecki, R. TNF- $\alpha$ stimulates Akt by a distinct aPKC-dependent pathway in premalignant keratinocytes. Exp. Dermatol. 2008, 17, 992-997. [CrossRef]

42. Patel, N.A.; Kaneko, S.; Apostolatos, H.S.; Bae, S.S.; Watson, J.E.; Davidowitz, K.; Chappell, D.S.; Birnbaum, M.; Cheng, J.Q.; Cooper, D.R. Molecular and Genetic Studies Imply Akt-mediated Signaling Promotes Protein Kinase C $\beta$ II Alternative Splicing via Phosphorylation of Serine/Arginine-rich Splicing Factor SRp40. J. Biol. Chem. 2005, 280, 14302-14309. [CrossRef] [PubMed]

43. Sahebi, M.; Hanafi, M.M.; van Wijnen, A.J.; Azizi, P.; Abiri, R.; Ashkani, S.; Taheri, S. Towards understanding pre-mRNA splicing mechanisms and the role of SR proteins. Gene 2016, 587, 107-119. [CrossRef] [PubMed]

44. Zhou, Z.; Fu, X.-D. Regulation of splicing by SR proteins and SR protein-specific kinases. Chromosoma 2013, 122, $191-207$. [CrossRef] [PubMed]

45. Gonçalves, V.; Matos, P.; Jordan, P. Antagonistic SR proteins regulate alternative splicing of tumor-related Rac1b downstream of the PI3-kinase and Wnt pathways. Hum. Mol. Genet. 2009, 18, 3696-3707. [CrossRef] [PubMed]

46. Erkelenz, S.; Mueller, W.F.; Evans, M.S.; Busch, A.; Schöneweis, K.; Hertel, K.J.; Schaal, H. Position-dependent splicing activation and repression by SR and hnRNP proteins rely on common mechanisms. RNA 2012, 19, 96-102. [CrossRef] [PubMed] 
47. Cáceres, J.F.; Stamm, S.; Helfman, D.M.; Krainer, A.R. Regulation of Alternative Splicing in Vivo by Overexpression of Antagonistic Splicing Factors. Science 1994, 265, 1706-1709. [CrossRef]

48. Mayeda, A.; Krainer, A.R. Regulation of alternative pre-mRNA splicing by hnRNP A1 and splicing factor SF2. Cell 1992, 68, 365-375. [CrossRef]

49. Pascual, G.; Fong, A.L.; Ogawa, S.; Gamliel, A.; Li, A.C.; Perissi, V.; Rose, D.W.; Willson, T.M.; Rosenfeld, M.G.; Glass, C.K. A SUMOylation-dependent pathway mediates transrepression of inflammatory response genes by PPAR- $\gamma$. Nature 2005, 437, 759-763. [CrossRef] [PubMed]

50. Bassaganya-Riera, J.; Misyak, S.; Guri, A.J.; Hontecillas, R. PPAR $\gamma$ is highly expressed in F4/80hi adipose tissue macrophages and dampens adipose-tissue inflammation. Cell. Immunol. 2009, 258, 138-146. [CrossRef] [PubMed]

51. Charo, I.F. Macrophage Polarization and Insulin Resistance: PPAR $\gamma$ in Control. Cell Metab. 2007, 6, 96-98. [CrossRef] [PubMed]

52. Wong, N.H.; Kwang Tan, A.Y.; Chen, Y.; Sekar, K.; Tan, P.Y.; Chan, D.; Chiang, K.; Wong, N.C. Thermal evaluation of vertical greenery systems for building walls. Build. Environ. 2010, 45, 663-672. [CrossRef]

53. Viglietti, A.I.P.; Giambartolomei, G.H.; Quarleri, J.; Delpino, M.V. Brucella abortus Infection Modulates 3T3-L1 Adipocyte Inflammatory Response and Inhibits Adipogenesis. Front. Endocrinol. 2020, 11, 755. [CrossRef] [PubMed]

54. Lacasa, D.; Taleb, S.; Keophiphath, M.; Miranville, A.; Clement, K. Macrophage-Secreted Factors Impair Human Adipogenesis: Involvement of Proinflammatory State in Preadipocytes. Endocrinology 2007, 148, 868-877. [CrossRef]

55. Batista, T.M.; Jayavelu, A.K.; Albrechtsen, N.J.W.; Iovino, S.; Lebastchi, J.; Pan, H.; Dreyfuss, J.M.; Krook, A.; Zierath, J.R.; Mann, M.; et al. A Cell-Autonomous Signature of Dysregulated Protein Phosphorylation Underlies Muscle Insulin Resistance in Type 2 Diabetes. Cell Metab. 2020, 32, 844-859.e5. [CrossRef]

56. Vernia, S.; Edwards, Y.J.; Han, M.S.; Cavanagh-Kyros, J.; Barrett, T.; Kim, J.K.; Davis, R.J. An alternative splicing program promotes adipose tissue thermogenesis. eLife 2016, 5, e17672. [CrossRef] [PubMed]

57. Pihlajamäki, J.; Lerin, C.; Itkonen, P.; Boes, T.; Floss, T.; Schroeder, J.; Dearie, F.; Crunkhorn, S.; Burak, F.; Jimenez-Chillaron, J.C.; et al. Expression of the Splicing Factor Gene SFRS10 Is Reduced in Human Obesity and Contributes to Enhanced Lipogenesis. Cell Metab. 2011, 14, 208-218. [CrossRef]

58. Prabhu, S.; Deng, H.; Cross, T.-W.L.; Shahoei, S.H.; Konopka, C.J.; Medina, N.G.; Applegate, C.C.; Wallig, M.A.; Dobrucki, L.W.; Nelson, E.R.; et al. Nanocarriers targeting adipose macrophages increase glucocorticoid anti-inflammatory potency to ameliorate metabolic dysfunction. Biomater. Sci. 2020, 9, 506-518. [CrossRef]

59. Aprile, M.; Ambrosio, M.R.; D’Esposito, V.; Beguinot, F.; Formisano, P.; Costa, V.; Ciccodicola, A. PPARGin Human Adipogenesis: Differential Contribution of Canonical Transcripts and Dominant Negative Isoforms. PPAR Res. 2014, 2014, 537865. [CrossRef] 